\title{
Attribution of stratospheric ozone trends to chemistry and transport: a modelling study
}

\author{
G. Kiesewetter ${ }^{1}$, B.-M. Sinnhuber ${ }^{1, *}$, M. Weber $^{1}$, and J. P. Burrows ${ }^{1}$ \\ ${ }^{1}$ Institute of Environmental Physics, University of Bremen, Otto-Hahn-Allee 1, 28359 Bremen, Germany \\ *now at: Karlsruhe Institute of Technology, Institute for Meteorology and Climate Research, Karlsruhe, Germany
}

Received: 4 June 2010 - Published in Atmos. Chem. Phys. Discuss.: 20 July 2010

Revised: 26 November 2010 - Accepted: 30 November - Published: 17 December 2010

\begin{abstract}
The decrease of the concentration of ozone depleting substances (ODSs) in the stratosphere over the past decade raises the question to what extent observed changes in stratospheric ozone over this period are consistent with known changes in the chemical composition and possible changes in atmospheric transport. Here we present a series of ozone sensitivity calculations with a stratospheric chemistry transport model (CTM) driven by meteorological reanalyses from the European Centre for Medium-Range Weather Forecasts, covering the period 1978-2009. In order to account for the reversal in ODS trends, ozone trends are analysed as piecewise linear trends over two periods, 1979-1999 and 2000-2009. Modelled column ozone (TO3) inter-annual variability and trends are in excellent agreement with observations from the Total Ozone Mapping Spectrometer (TOMS) and Solar Backscatter UV (SBUV/2) as well as the Global Ozone Monitoring Experiment (GOME/GOME2) and Scanning Imaging Absorption Spectrometer for Atmospheric Chartography (SCIAMACHY) instruments. In the period 1979-1999, modelled TO3 trends at mid-latitudes are dominated by changes in in situ gas-phase chemistry, which contribute to about $50 \%$ or more of the TO3 trend in most seasons. Changes in meteorology contribute around 35\% to mid-latitude TO3 trends, with strong differences between different seasons. In springtime, export of ozone depleted air from polar latitudes contributes about $35-50 \%$ to the modelled TO3 trend at SH mid-latitudes and about $15-30 \%$ at NH mid-latitudes. Over the period 2000-2009 positive linear trends in modelled TO3, which agree well with observed TO3 trends, are dominated by changes in meteorology, as expected for the yet small decrease in stratospheric halogen loading over this period. While the TO3 trends themselves
\end{abstract}

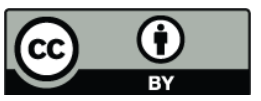

Correspondence to: G. Kiesewetter (gregor.kiesewetter@iup.physik.uni-bremen.de) are not statistically significant over the period 2000-2009, changes in linear trends between 1978-1999 and 2000-2009 are significant at mid- and high latitudes of both hemisphere during most seasons. However, changes in meteorology have contributed substantially to these TO3 trend changes.

\section{Introduction}

Stratospheric ozone has shown large decreases during past decades, mainly attributable to the anthropogenic input of ozone depleting substances (ODSs) such as chlorofluorocarbons (CFCs) (e.g., World Meteorological Organization, 2007). The mechanisms of chemical ozone depletion have been studied extensively and are well understood, leading to the abolition of production of the responsible substances by the Montreal Protocol in 1986 and subsequent amendments and adjustments. Since the turn of the century, stratospheric concentrations of ODSs have begun to decrease. As a result, an onset of recovery of the ozone layer is expected (Newman et al., 2006; World Meteorological Organization, 2007).

Some studies have reported the first stage of ozone recovery (i.e., a statistically significant change in ozone trend) (Newchurch et al., 2003; Yang et al., 2008; Reinsel et al., 2005).

In order to obtain a better understanding of a possible onset of recovery, a diligent attribution of ozone trends to different contributing factors is necessary. Main actors contributing to ozone trends are changing gas phase chemistry, changing polar chemistry and export of ozone-depleted air to lower latitudes, variations in stratospheric aerosol loading, and changes in stratospheric transport and temperatures. As ozone concentrations feed back on the circulation through changes in radiative heating, "chemical" and "dynamical" effects can never be fully separated (Braesicke

Published by Copernicus Publications on behalf of the European Geosciences Union. 
and Pyle, 2003). Several studies have attempted to quantify dynamical and chemical influences on past ozone trends, focusing mainly on Northern Hemisphere (NH) mid-latitudes (Solomon et al., 1996, 1998; Hood et al., 1997; Hadjinicolaou et al., 2002; Chipperfield, 2003).

Negative ozone trends from 1979 to the late 1990s have been mainly attributed to increases in stratospheric ODS loading during that period (Chipperfield, 2003); also the eruption of mount Pinatubo in 1991 contributed to recordlow ozone values in the 1990s (Randel et al., 1995). So far, only very few model studies have explicitly addressed the question of identifying ozone trend changes as a consequence of the turnaround in stratospheric chlorine loading at the end of the 20th century. Hadjinicolaou et al. (2005) analysed modelled ozone trends in two periods (1979-1993 and 1994-2003) and showed that most of the apparent recovery trend in 1994-2003 is attributable to meteorology. In a similar study, Stolarski et al. (2006) emphasized the difficulties in identifying signs of ozone recovery due to inter-annual variability. Several studies on observed ozone trends have shown that increases in NH total ozone since the middle 1990s were mainly driven by changes in transport and dynamics and to a lesser extent from changes in ozone depleting substances (Dhomse et al., 2006; Wohltmann et al., 2007; Harris et al., 2008).

In this study we have performed a series of sensitivity calculations with a chemistry transport model (CTM; Sinnhuber et al., 2003) over the past 32 years (1978-2009). In the model runs, polar chemistry and gas-phase chemistry are switched between the states "constant chemical composition" and "time-dependent chemical composition". In addition, a reference run without polar chemistry was conducted. Differences in ozone amounts and trends between the different runs thus allow us to distinguish the influences of polar heterogeneous chemistry and its export, gas phase chemistry, and meteorology (through temperature and transport). Thus, our study includes most of the agents influencing ozone variability, while ignoring direct influence of the solar cycle and volcanic eruptions (indirectly, these effects are partly included through the external wind fields that drive the CTM). In our analysis, we apply a linear regression model with piecewise linear trends which allows for a change in trend between the "increasing stratospheric halogen loading" phase (1979-1999) and the "decreasing stratospheric halogen loading" phase (2000-2009). Thus, we are able to explicitly address the question of how ozone (column and profile) trends are affected by the reversal of ODS trends, and whether observed changes in stratospheric ozone over this period are consistent with known changes in the chemical composition of the stratosphere and meteorology.

The outline of this paper is as follows. In Sect. 2, the model and its integrations are described. Section 3 validates column ozone time series against satellite observations; the roles of solar variations and aerosols is analysed in Sect. 4. In Sect. 5, a regression analysis of column and profile ozone trends is presented. Results are further discussed in Sect. 6, which attempts a more thorough decomposition of column ozone trends into contributions from different processes.

\section{Model and integrations}

\subsection{CTM}

Our stratospheric CTM (Sinnhuber et al., 2003) is run at a horizontal resolution of $3.75^{\circ} \cdot 2.5^{\circ}$. It uses 24 isentropic levels as vertical coordinates, ranging from $330 \mathrm{~K}$ to $3000 \mathrm{~K}$ (roughly $10-55 \mathrm{~km}$ ). Horizontal transport is driven by analysed wind fields and temperatures from the European Centre for Medium-Range Weather Forecasts (ECMWF) - in this study, we use ERA-40 data 1979-1999 and ERA-Interim 1989-2009. Vertical transport is derived directly from interactively calculated diabatic heating rates using the MIDRAD scheme (Shine, 1987).

\subsection{Gas phase chemistry}

We use a time-dependent version of the linearized ozone chemistry ("Linoz v2") described by Hsu and Prather (2009), an update to the Linoz scheme introduced by McLinden et al. (2000) which has been used in our CTM before (Kiesewetter et al., 2010). Although this chemistry scheme is simple, using only one ozone tracer and net production rates parameterized according to ozone volume mixing ratio $\left(\mathrm{O}_{3}\right)$, temperature $(T)$, and ozone column above the respective grid cell (CO3), it has been shown to generate realistic ozone fields (Hsu and Prather, 2009).

Dependencies of the net ozone production rate $P-L$ on the deviations of $\mathrm{O}_{3}, T$, and $\mathrm{CO} 3$ from their climatological values $\mathrm{O}_{3 \text { clim }} T_{\text {clim }}$, and $\mathrm{CO}_{\text {clim }}$ are tabulated according to month, latitude and geopotential height. From $\mathrm{O}_{3}-\mathrm{O}_{3} \mathrm{clim}$, $T-T_{\text {clim }}, \mathrm{CO} 3-\mathrm{CO} 3_{\text {clim }}$, a photochemical steady state ozone vmr $\left(\mathrm{O}_{\text {ss }}\right.$, equilibrium ozone vmr in the absence of transport) is calculated, against which $\mathrm{O}_{3}$ then relaxes with a time constant $\tau_{\text {Linoz }}=-\left(\left.\frac{\partial(P-L)}{\partial \mathrm{O}_{3}}\right|_{\text {clim }}\right)^{-1}$.

Linoz coefficients are based on calculations with a complete photochemical box model (Prather, 1992) that uses a climatological chemical composition scaled to the tropospheric abundance of long-lived source gases $\left(\mathrm{N}_{2} \mathrm{O}, \mathrm{CH}_{4}\right.$, and halocarbons). Tropospheric source gas mixing ratios are taken from the A1 scenario of the upcoming CCMVal 2 Report (Eyring et al., 2010).

In order to account for the changing atmospheric composition during the period of interest (in particular, rising and falling equivalent effective stratospheric chlorine, EESC), we use three different Linoz tables instead of one. They were generated for stratospheric trace gas concentrations corresponding to the years 1978, 2000, and 2010 (more specifically, to tropospheric concentrations of three years earlier, in order to account for the mean stratospheric age of air). 
These years are chosen as the first and last years of the model integrations, and a "peak-EESC" year in between. The tables are then interpolated linearly in time, leading to a linear increase of EESC by a factor of 2 between 1978 and 1999, and a linear decrease by $\sim 10 \%$ until 2009. Since stratospheric chlorine peaked at different times depending on latitude and height, the selection of 1999/2000 as the transition from rising to falling EESC loadings is a compromise between high and low latitudes. Due to the length of the time period analysed in this study, ozone trends are not expected to be influenced substantially by small variations in "peak-EESC" year.

Although Linoz does include mid-latitude heterogeneous ozone chemistry on aerosols, aerosol levels are kept at background levels in this study (year 1990 of the SAGE II climatology, Thomason et al., 1997). For simplicity, we refer to ozone changes induced by Linoz through changing chemical composition as "changes in gas-phase chemistry" throughout this study. Linoz does not account for polar heterogeneous chemistry taking place on polar stratospheric clouds.

\subsection{Polar chemistry}

The effects of heterogeneous ozone destruction are included in our CTM in the form of a simple parameterized polar chemistry as described by Kiesewetter et al. (2010). When conditions for polar stratospheric cloud (PSC) formation are met, i.e. when $T<T_{\mathrm{NAT}}$ with $T_{\mathrm{NAT}}$ the critical temperature for onset of Nitric Acid Trihydrate (NAT) formation, and enough sunlight is present, ozone is destroyed at a defined rate. Parameters used here are modified slightly from Kiesewetter et al. (2010): ozone lifetime (year 2000) $\tau=10$ days and critical solar zenith angle $\theta=92.5^{\circ}$.

In order to account for the changing concentrations of ODSs in the stratosphere during the period of our model integrations, we scale the ozone decay rate $1 / \tau$ with the effective equivalent stratospheric chlorine (EESC), calculated as described by Newman et al. (2006) (Age of air $=5.5 \mathrm{yr}$, Age spectrum width $=2.75 \mathrm{yr}$, Bromine scaling factor $\alpha=50$ ). This EESC curve almost doubles between 1978 and 2000, peaks in 2001, and then decreases by $\sim 5 \%$ until 2009 .

The dependence of the ozone decay rate on EESC is usually estimated to be close to linear (Harris et al., 2010); however, there are also arguments in favor of a stronger dependence (Searle et al., 1998; Hsu and Prather, 2009). Reasonable values for the exponent $n\left(1 / \tau \propto \mathrm{EESC}^{n}\right)$ range between 1 and 2 (Searle et al., 1998). Model runs analyzed in this paper generally use either $1 / \tau \propto$ EESC or constant year 2000 conditions. In order to obtain an upper estimate for trends related to polar chemistry, one additional model run uses a higher scaling of $1 / \tau \propto \mathrm{EESC}^{2}$.
Table 1. Model runs analysed in this paper, distinguished by the gas phase chemistry (Linoz) mode and polar chemistry (polarchem) mode used. For details see text.

\begin{tabular}{cll}
\hline Run & Linoz & polar chemistry \\
\hline$t t$ & changing ODS levels & $1 / \tau \propto$ EESC \\
$t T$ & changing ODS levels & $1 / \tau \propto$ EESC $^{2}$ \\
$c t$ & constant ODS levels (2000) & $1 / \tau \propto$ EESC $^{-}$ \\
$t c$ & changing ODS levels & constant EESC (2000) \\
$c c$ & constant ODS levels (2000) & constant EESC (2000) \\
$t n$ & changing ODS levels & off \\
\hline
\end{tabular}

\subsection{Model integrations}

Six CTM runs were performed in total, which are labeled here according to the gas-phase chemistry (Linoz) and the polar chemistry scheme used. Five runs use polar chemistry; in these, Linoz and polar chemistry were switched between changing atmospheric composition (as described above) and constant year 2000 conditions. The sixth run, which does not use polar chemistry, is used only as a reference run for diagnosing the effects of polar ozone loss.

Labels consist of two letters, the first of which corresponds to the gas phase chemistry scheme used and the second corresponds to polar chemistry scheme. Letters referring to gas-phase chemistry are " $t$ " for time-dependent and " $c$ " for constant year 2000 conditions. Letters describing the polar chemistry mode are " $t$ " for time-dependent with $1 / \tau \propto$ EESC, " $T$ " for time-dependent with $1 / \tau \propto \mathrm{EESC}^{2}$, " $c$ " for constant year 2000 conditions ( $\tau=10 \mathrm{~d}$ ), and " $n$ " for none.

An overview of the model runs is provided in Table 1. All model runs were performed in two parts, 1978-1999 (using ERA-40 data) and 1989-2009 using ERA-Interim. A long overlap period using different meteorological analyses is desirable in order to quantify offsets in ozone concentrations due to differences in the meteorological datasets, such as discussed by e.g. Chipperfield (2003) and later in this paper. The runs starting in January 1978 are initialized from an ozone climatology (Fortuin and Kelder, 1998), while the runs starting January 1989 use output from the corresponding ERA-40 driven run as initial conditions. In both cases, the first year is discarded in the analysis in order to account for initial spin-up and meteorological transition.

\section{Comparison to TOMS/SBUV and GOME/SCIAMACHY/GOME2 column ozone}

As a first step, we have to establish that the CTM with EESC-varying chemistry represents observed ozone well. Here we show a comparison of modelled column ozone (TO3) to observations from the Total Ozone Mapping Spectrometer and Solar Backscatter UV (TOMS/SBUV) merged dataset (Stolarski and Frith, 2006), as well as the 
GOME/SCIAMACHY/GOME2 merged dataset ("GSG" in the following) which has been compiled from observations made by the Global Ozone Monitoring Experiment (GOME) (Coldewey-Egbers et al., 2005; Weber et al., 2005), the Scanning Imaging Absorption Spectrometer for Atmospheric Chartography (SCIAMACHY) (Bovensmann et al., 1999; Bracher et al., 2005), and GOME2 (Callies et al., 2000) instruments. In the GSG merged data set the SCIAMACHY (2002-present) and GOME2 (2007-present) data have been adjusted to the GOME data record (1995-present) by determining a mean scaling factor (GOME2 and SCIAMACHY) and trend (SCIAMACHY only) in the monthly mean zonal mean ratios. Using the criterion of optimum global sampling the GSG data set is then composed of GOME1 until 2003, SCIAMACHY (2003-2006), and GOME2 after 2006. The GSG data set is described at and available from http://www. iup.uni-bremen.de/gome/wfdoas/wfdoas $\backslash$ merged.html (see also Weber et al., 2007).

Figure 1 shows time series of annual mean model TO3 (ERA-40 and ERA-Interim driven runs separately) together with TOMS/SBUV and GSG for mid-latitudes and tropics. In order to enable comparison with satellite observations, the climatological ozone column below $330 \mathrm{~K}$ (taken from the climatology of Fortuin and Kelder, 1998) is added to modelled TO3. In addition to the $t t$ run, also the $t T$ run with stronger EESC dependence of polar chemistry is shown. Modelled ozone is generally higher than the observations, with a distinct difference between the different meteorological datasets (note the shifted right-hand side axes regarding modelled TO3 during the different periods). The fact that switching meteorological analyses during a model run can lead to considerable artifacts in modelled ozone has been reported before, e.g. by Feng et al. (2007) at the transition between ERA-40 and operational analyses. In our model, mean offsets are +19 DU (+40 DU) in NH midlatitudes, +3 DU (+6 DU) in the tropics, and +22 DU (+33 DU) in SH midlatitudes for ERA-40 (ERA-Interim) meteorological fields. Ozone variability is represented well especially in the 19791999 period (ERA-40) and in the 2000-2009 period (ERAInterim), while the ERA-Interim driven run does not fully capture the decadal-scale increase in TO3 around the turn of the century.

The good agreement between model and observations is underscored by high correlation coefficients between model and observed TO3 time series for all months and latitudes, as shown in Fig. 2 for TOMS/SBUV in the interval 1978-1999 (CTM driven by ERA-40 data, upper panel) and for GSG in the 1995-2009 interval (CTM driven by ERA-Interim data, lower panel). For the ERA-40 driven run, correlation coefficients are higher than 0.7 for most of the $\mathrm{NH}$, higher than 0.8 in the inner tropics, and higher than 0.9 for Antarctic spring. In the case of the ERA-Interim driven run, most features are similar; correlation in the inner tropics and throughout midlatitude/polar spring and summer is excellent, while the model seems to have some difficulties in reproducing sub-
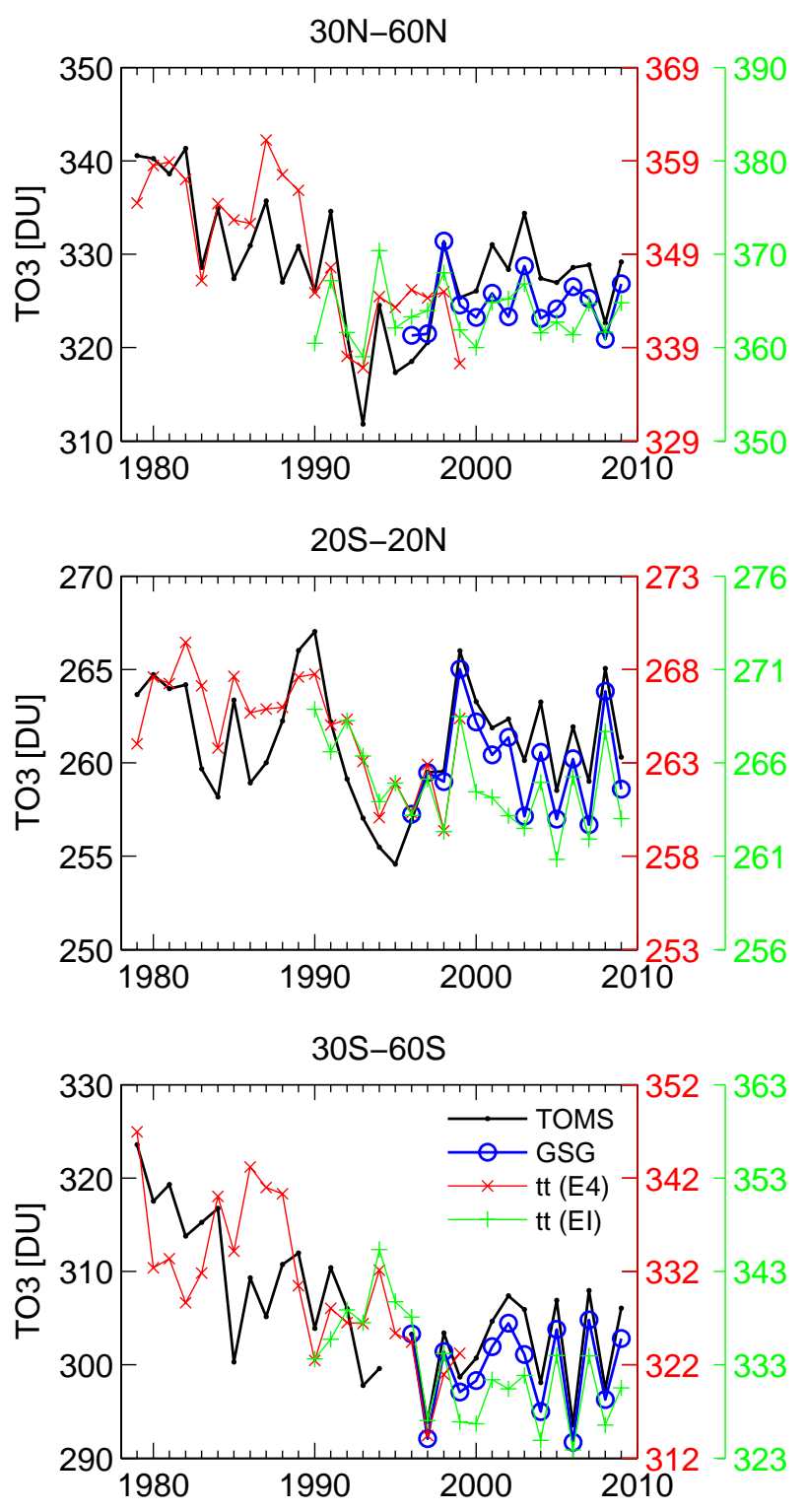

Fig. 1. Total ozone (TO3) annual means from the $t t$ (time-dependent chemistry) model run, as compared to the TOMS/SBUV merged TO3 dataset ("TOMS") and the GOME/SCIAMACHY/GOME2 merged datasets ("GSG”). Model runs are performed in two periods, 1979-1999 using ERA-40 data $($ red $\times$ ), and 1990-2009 using ERA-Interim (green + ). Modelled TO3 shows different offsets to satellite observations during the two periods, which are accounted for by the shifted right-hand axes (middle axis 1979-1999, far right axis 1990-2009). The climatological ozone column below $330 \mathrm{~K}$ has been added to modelled TO3.

tropical $\left(\sim 30^{\circ}\right)$ ozone variability for single months (mainly September in the NH and March in the SH).

Figure 3 illustrates the variability of polar ozone in our CTM. Here TO3 time series from the $t t$ CTM run averaged 
TOMS/SBUV vs CTM, 1979-1999 (ERA40)
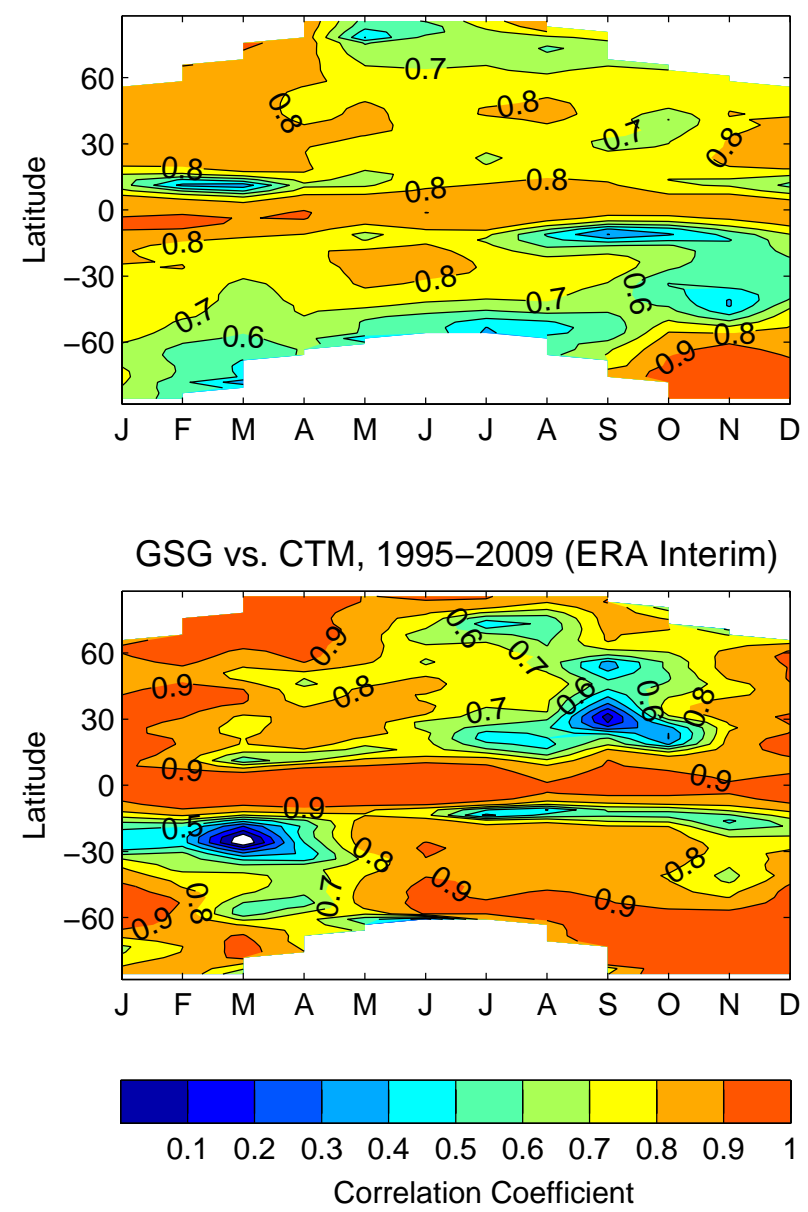

Fig. 2. Correlation between observed and modelled TO3 ( $t t)$ monthly mean time series: TOMS/SBUV vs. CTM in the period 1979-1999 (upper panel, model driven by ERA-40) and GOME/SCIAMACHY/GOME2 vs. CTM in the period 1990-2009 (lower panel, model driven by ERA-Interim).

poleward of $63^{\circ}$ (corrected for TO3 below $330 \mathrm{~K}$ ) are compared to satellite observations from the TOMS/SBUV and GSG merged ozone datasets. In addition, the $t T$ run is shown, which has a polar ozone decay rate $\propto \mathrm{EESC}^{2}$. The observed polar ozone variability is captured very well by the CTM. Considerable differences in SH polar TO3 evolution are visible between $t t$ and $t T$. While $t t$ slightly underestimates the magnitude of the observed trend, $t T$ shows a stronger negative trend than the observations. Hence, the two runs $t t$ and $t T$ may be regarded as both extremes of Antarctic TO3 evolution and are both analysed in this study.

Polar heterogeneous chemistry leads to severe ozone depletion during winter and spring, after which the air masses are exported to lower latitudes. In our CTM, the magnitude of polar ozone loss can be diagnosed by comparing model runs with polar chemistry $(t t, t c, t T)$ to the reference run $t n$ without polar chemistry.

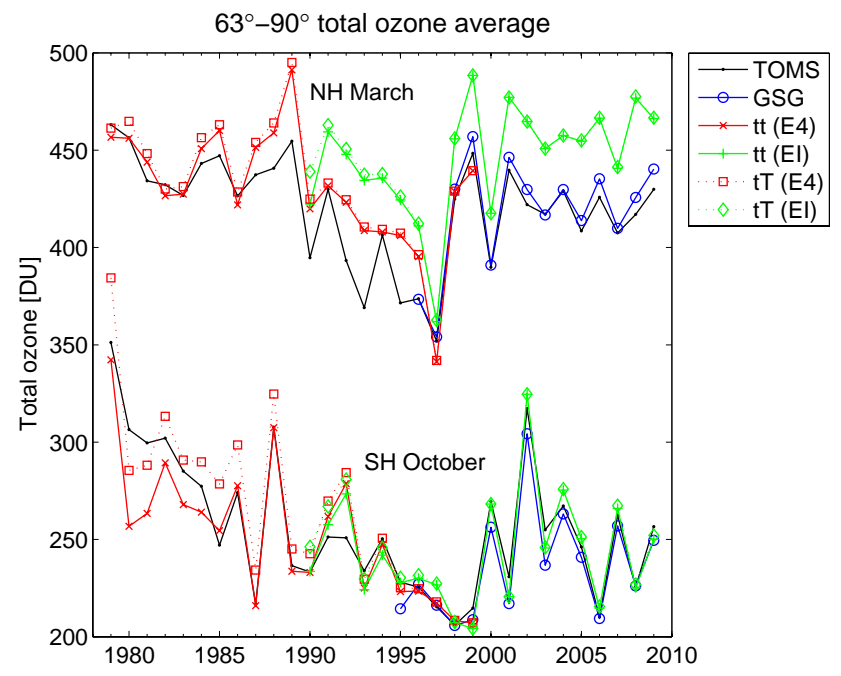

Fig. 3. Springtime polar TO3 from model runs with EESCdependent chemistry, as compared to the TOMS/SBUV merged TO3 dataset ("TOMS") and the GOME/SCIAMACHY/GOME2 merged datasets ("GSG"). In addition to the $t t$ model runs using a polar chemistry scheme scaled linearly with EESC, also the $t T$ model runs are shown, which use a polar chemistry $\propto \mathrm{EESC}^{2}$. Model runs are performed in two periods, 1979-1999 using ERA40 wind fields ("E4"), and 1990-2009 using ERA-Interim ("EI"). The climatological ozone column below $330 \mathrm{~K}$ has been added to modelled TO3.

The year-to-year variability of polar ozone losses depends largely on the meteorological conditions during winter (Rex et al., 2004; Weber et al., 2003). A comparison of polar ozone losses in the CTM to observed results reported by World Meteorological Organization (2007) shows that the model generally captures the variability of $\mathrm{NH}$ losses well, but underestimates the magnitude. Values obtained in cold Arctic winters with strong ozone depletion such as $1995 / 1996$ or $1999 / 2000$ are around $50-60$ DU in the CTM, while the WMO assessment gives values of $80-100 \mathrm{DU}$ in these years. The main reason for this behaviour lies in the construction of our polar chemistry scheme, which destroys ozone only while temperatures are cold enough for PSC formation. Thus effects of activated chlorine are missed which may occur after PSCs themselves are no longer formed, especially in a denitrified vortex (Waibel et al., 1999).

Exact amounts of ozone losses are difficult to quantify with our simple polar chemistry scheme, as considerable differences between ERA-40 and ERA-Interim reanalyses are encountered. Analysing the long-term evolution of polar ozone losses in our CTM, we find that although losses increase in time, substantial polar ozone loss is already present around 1980 in both $t t$ and $t T$ runs. However, an exact quantification of early TO3 losses is not attempted here, as a detailed polar chemistry scheme should be used for this purpose. 


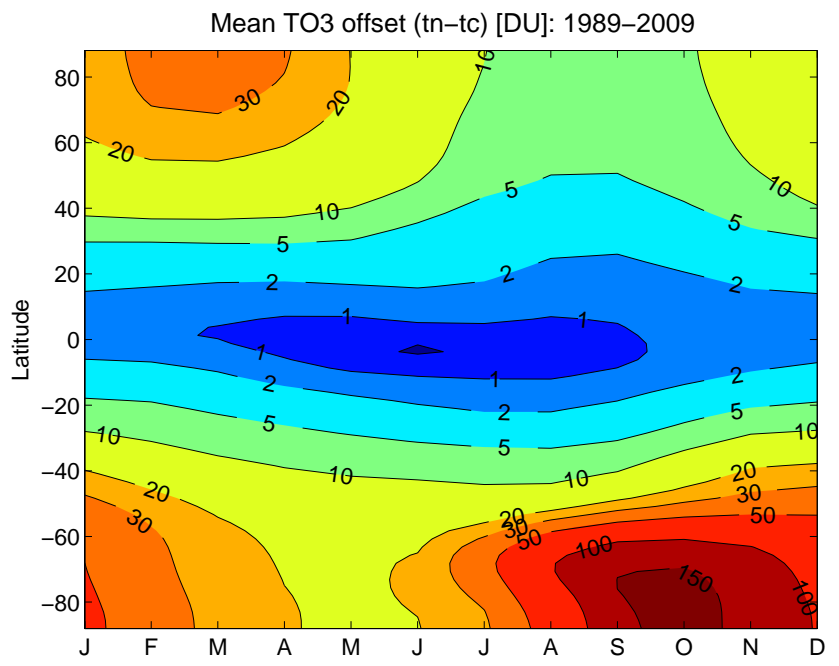

Fig. 4. TO3 offsets due to polar ozone depletion and its export (differences of runs $t n-t c$ ), given in DU for all latitudes and months, averaged over the ERA-Interim driven period (1989-2009).

A climatology of the TO3 offsets induced globally by polar ozone depletion and dilution of ozone-depleted air is shown in Fig. 4. A residual effect of polar chemistry persists at all latitudes and does not vanish throughout the year. The minimal values of these offsets amount to around 25 DU in the northern mid-latitudes (June-September), 1$2 \mathrm{DU}$ in the tropics, and $8-15 \mathrm{DU}$ in the southern midlatitudes (March-August).

\section{Solar and aerosol effects}

A significant part of the decadal-scale deviations between modelled and measured TO3 in Fig. 1 is related to the 11 year solar cycle, which is not directly accounted for in our CTM. Changes in solar activity lead to variations in column ozone in the order of 2-3\% (solar maximum - solar minimum, in phase with the solar flux) due to an enhancement of oddoxygen production in the middle to upper stratosphere during high solar activity (Chipperfield, 2003; Soukharev and Hood, 2006).

In addition to variations in solar irradiation, also variations in volcanic aerosols, which are not included in our CTM, contribute to differences between modelled and observed ozone. We quantify their influence by regressing the monthly deseasonalized time series of $\Delta \mathrm{TO} 3:=\mathrm{TOMS} / \mathrm{SBUV}-t t$ (ERA-40 and ERA-Interim driven part concatenated) against a simple model,

$$
\begin{aligned}
\Delta \operatorname{TO} 3(t)= & \mu+\omega_{0} \Theta\left(t-t_{0}\right)+\chi_{1} F_{10.7}(t-\Delta t) \\
& +\chi_{2} \operatorname{AOD}(t)+N(t),
\end{aligned}
$$

which contains a constant offset $\mu$, a step function $\Theta\left(t-t_{0}\right)$ at the transition of the meteorological datasets $(\Theta=0$ for the

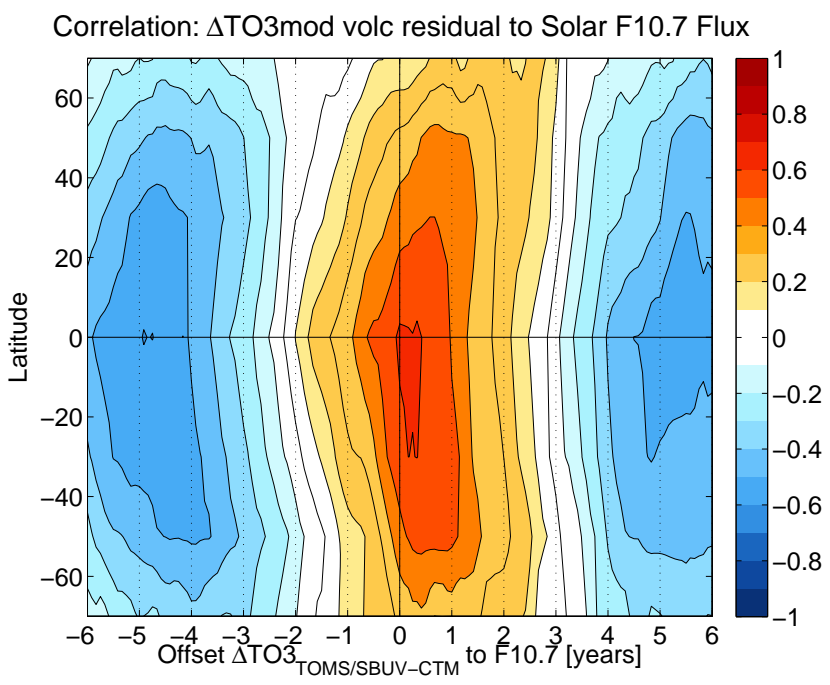

Fig. 5. Correlation between the residuals of the "aerosol only" regression of TOMS/SBUV $-t t$ offsets and the Solar $F_{10.7}$ radio flux, for different time delays between $\Delta \mathrm{TO} 3$ and $F_{10.7}$. The regressed time series is shown in Fig. 6.

ERA-40 period and $\Theta=1$ for the ERA-Interim period), the solar $10.7 \mathrm{~cm}$ radio flux time series $\left(F_{10.7}\right)$, and the $1000 \mathrm{~nm}$ aerosol optical depth $\operatorname{AOD}(t)$ (taken from the SAGE dataset provided through the SPARC data center, see Thomason and Peter (2006), and extended at constant levels after 2002). $N(t)$ represents the unexplained noise. The solar proxy is used with a latitude-dependent time shift that is determined by maximum correlation of fit residuals without $F_{10.7}$ to the $F_{10.7}$ flux. This correlation is shown in Fig. 5 as a function of latitude and time delay between $\Delta \mathrm{TO} 3$ and $F_{10.7}$. A distinct pattern of high correlation in phase with the solar cycle is visible, which maximises near the equator at little or no delay (correlation coefficient $>0.6$ ), and is delayed by a few months and up to one year in the midlatitudes. Correlation coefficients are higher than 0.4 up to $50^{\circ} \mathrm{N}$ and $60^{\circ} \mathrm{S}$. Delays which exhibit maximum correlation are used as the time shift in Eq. (1).

Results from the regression of $\Delta \mathrm{TO} 3$ (Eq. 1) are presented in Fig. 6. shows the $\triangle \mathrm{TO} 3$ time series (black line), along with the regressed $\widehat{\triangle \mathrm{TO} 3}$ obtained from Eq. (1) (red dashed line). In addition, we show $\widehat{\triangle \mathrm{TO} 3}$ obtained from regression without a solar term (blue line), as well as without the aerosol proxy (green line). The full regression model reproduces the TO3 observed offsets well, particularly in the tropics. Best agreement is observed when the full regression with both aerosol and solar terms is used. In the tropics, residuals are considerably smaller in the reduced model without $F_{10.7}$ flux as compared to the reduced model without aerosols, pointing to the possibly larger relative importance of volcanic aerosols. 
The regression model described above allows us to generate an observational time series of TOMS/SBUV and GSG TO3 with solar and aerosol signals removed, which is thus better comparable with modelled TO3. The regression is performed separately for TOMS/SBUV and GSG. The resulting TOMS/SBUV and GSG column ozone time series with solar and aerosol terms removed are then used for the trend analysis presented in Sect. 5.2.

\section{Trend analysis}

\subsection{Methodology}

In our analysis of ozone trends we follow largely the method of piecewise linear trends as described by Reinsel et al. (2002). The primary focus of the analysis is to obtain seasonal ozone trends, which are calculated as seasonal averages of monthly trends. We analyse the whole time series of modelled ozone in one piece, concatenating the ozone time series obtained with ERA-40 and ERA-Interim data. Let $Y(t)$ be a time series of monthly mean ozone with an annual interval, $t$ running from 1 to 42 (21 years ERA-40 driven CTM output plus 21 years ERA-Interim driven CTM output). Then the regression model used is of the form

$Y(t)=\mu+\omega_{0} \Theta\left(t-t_{0}\right)+\omega_{1} X_{1}(t)+\omega_{2} X_{2}(t)+N(t)$,

where $\mu$ is a constant (mean level), $\Theta$ is a Heaviside step function that accounts for the offset $\omega_{0}$ induced by different meteorological fields $(\Theta=0$ for the ERA-40 period and $\Theta=1$ for the ERA-Interim period), $X_{1}(t)$ is a linear trend function, and $X_{2}(t)$ represents an additional linear trend function ("change in trend") that is zero before Jan 2000 and increases linearly afterwards.

The trend function $X_{1}(t)$ is replicated during the overlap period of the different meteorological fields. Hence, the same linear trend is used for both ERA-40 and ERAInterim driven fields, while allowing for an offset due to the changed meteorology.

$N(t)$ represents the unexplained noise term, which is not autocorrelated here due to the use of annually spaced values. This simplifies the calculation of uncertainties of the fit coefficients. Equation (2) may be rewritten in matrix form as

$\boldsymbol{Y}=\mathbf{A} \cdot \boldsymbol{\omega}+\boldsymbol{N}$,

where $\mathbf{A}$ is the fit matrix, and $\boldsymbol{Y}, \boldsymbol{\omega}$ and $\boldsymbol{N}$ denote the vectors of ozone time series, fit coefficients, and residual noise. Inversion of Eq. (3) yields the generalized least squares estimator $\hat{\boldsymbol{\omega}}$ for the fit coefficients $\boldsymbol{\omega}$. The covariance matrix of the fit coefficients, $\sigma_{\hat{\omega}}{ }^{2}$, is derived from the standard error of the fit residuals, $\sigma_{N}=(\operatorname{Var}(N))^{1 / 2}$, as

$\boldsymbol{\sigma}_{\hat{\boldsymbol{\omega}}}^{2}=\left(\mathbf{A}^{\mathbf{T}} \mathbf{A}\right)^{-1} \cdot \sigma_{N}^{2}$
Standard errors of the different fit coefficients are obtained as square roots of the diagonal elements of $\sigma_{\hat{\omega}}{ }^{2}$, whereas the standard error of the combined trend $\hat{\omega}_{12}:=\hat{\omega}_{1}+\hat{\omega}_{2}$ is given by

$\sigma_{\hat{\omega}_{12}}=\left[\operatorname{Var}\left(\hat{\omega}_{1}\right)+\operatorname{Var}\left(\hat{\omega}_{2}\right)+2 \operatorname{Cov}\left(\hat{\omega}_{1}, \hat{\omega}_{2}\right)\right]^{1 / 2}$.

In the case of profile ozone (Sect. 5.3), the monthly deseasonalized $\mathrm{O}_{3}$ time series is analysed in one piece for every potential temperature level, without separation into time series for specific months of a year. Hence, the autocorrelation of the time series has to be taken into account for the calculation of the standard deviation of the trend estimates. Following Reinsel et al. (2002), we assume a 1 month autocorrelation model. $\sigma_{\hat{\omega}_{1}}, \sigma_{\hat{\omega}_{2}}$, and $\sigma_{\hat{\omega}_{12}}$ are then calculated as

$$
\begin{aligned}
& \sigma_{\hat{\omega}_{1}} \approx \frac{\sigma_{N}}{n^{3 / 2}} \sqrt{\frac{1+\phi}{1-\phi}} \\
& \sigma_{\hat{\omega}_{2}} \approx \frac{\sigma_{N}}{2} \sqrt{\frac{1+\phi}{1-\phi}}\left(\frac{n}{n_{0} n_{1}}\right)^{3 / 2},
\end{aligned}
$$

and

$\sigma_{\hat{\omega}_{12}} \approx \frac{\sigma_{N}}{n_{1}^{3 / 2}} \sqrt{\frac{1+\phi}{1-\phi}} \sqrt{\frac{n_{0}+4 n_{1}}{4 n}}$,

where $n_{0}$ is the number of years of data prior to the change in trend, $n_{1}$ is the number of years from the trend change, and $n=n_{0}+n_{1} . \phi$ is the autocorrelation of the residuals $N(t)$ with a timelag of 1 month,

$\phi=\operatorname{Corr}[N(t), N(t-1)]$.

\subsection{Column ozone trends}

In this section, seasonal trends of the column ozone time series are analysed as described in Sect. 5.1. The observational TO3 time series used here is a concatenation of TOMS/SBUV and GSG datasets with volcanic and solar signal removed as described in Sect. 4. TOMS/SBUV and GSG datasets are regressed here in one piece, in a similar fashion as the ERA-40 and ERA-Interim driven parts of the model runs, to arrive at a single trend estimate for "TOMS/GSG". While the same trend regression functions are used during the period of overlap, an offset between the two satellite time series is allowed, which is generally less than $5 \mathrm{DU}$.

Figure 7 shows the linear trend $\hat{\omega}_{1}$ of the EESC-varying model runs $(t t, t T)$, expressed here as percent change of 1980 values per year, along with its standard error. For comparison, the $c c$ trend is shown, which represents the effects of changing meteorology. In most latitudes and seasons, TO3 trends observed in model run $t t$ are in excellent agreement with trends in TOMS/GSG. In the seasons when polar ozone depletion is relevant, TOMS/GSG shows slightly stronger 

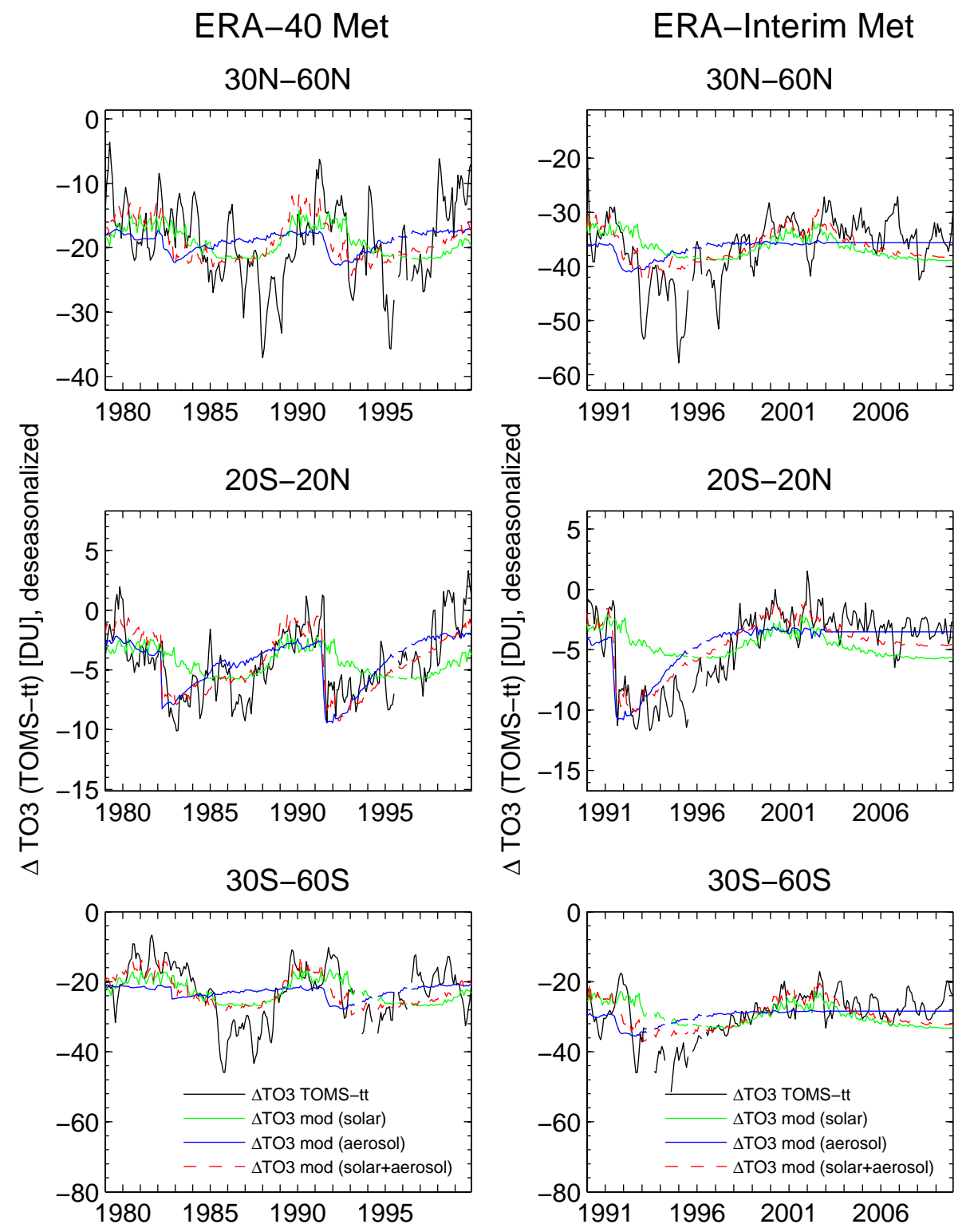

Fig. 6. Regression analysis of TO3 deviation (TOMS/SBUV observations - CTM run $t t$ ) to solar $F_{10.7}$ radio flux and SAGE aerosol optical depth. Left: ERA-40 driven model run (1979-1999), right: ERA-Interim driven model run (1990-2009). The actual deseasonalized TO3 offset between observations and model (black line) is shown along with the best fit including the solar proxy only (green line), the aerosol proxy only (blue line), and both (red dashed line).

TO3 losses, indicating that the linear scaling of the ozone destruction rate with EESC in $t t$ may underestimate the real proportionality. Thus, also trends from the $t T$ run are shown, in which the polar ozone destruction rate is scaled proportional to $\mathrm{EESC}^{2}$. In this case, negative TOMS/SBUV trends are over-matched in $\mathrm{SH}$ winter and spring, indicating that the optimal scaling for $1 / \tau$ with EESC should have an exponent between 1 and 2 .

Trends during this time period have been discussed extensively (e.g., Harris et al., 1998; World Meteorological Organization, 2007, and references therein). Trends are gener- ally zero near the equator (the model shows a slightly negative trend around the equator that is not present in the observations) and decrease to around -0.3 to $-0.5 \% \mathrm{yr}^{-1}$ in the extratropics, except for SH high latitudes in spring when large effects of heterogeneous ozone depletion are observed $\left(<-2 \% \mathrm{yr}^{-1}\right.$ in TOMS, somewhat less in $\left.t t\right)$. In this context, it is remarkable that also run $c c$ shows a distinct downward trend in TO3 in the SH polar spring (almost $50 \%$ of the $t t$ trend), which is a clear indication of a feedback of ozone depletion on the stratospheric circulation as discussed before by, e.g., Randel and Wu (1999). 


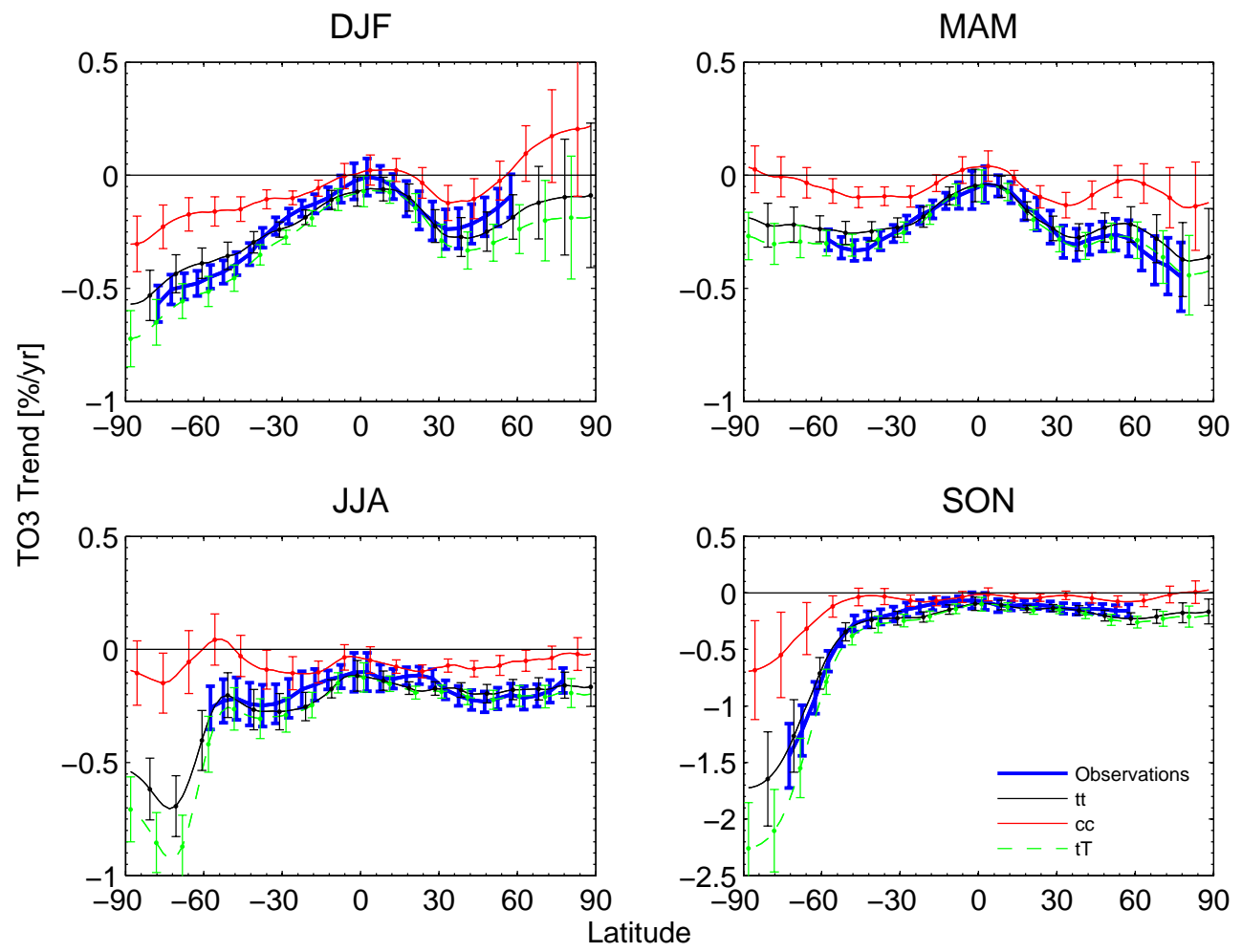

Fig. 7. Modelled TO3 trends in the period 1979-1999 as compared to the combined TOMS/SBUV + GOME/SCIAMACHY/GOME2 TO3 trends ("Observations"), obtained from the time series with solar and aerosol signals removed. Trends from model runs with EESC-dependent chemistry and polar chemistry ( $t t$, black line, and $t T$, green dashed line) and constant chemical conditions ( $c c$, red line) are shown. In $t T$, the polar ozone destruction rate is scaled $\propto \mathrm{EESC}^{2}$ while in $t t$, it is scaled $\propto$ EESC. Trends are given in percent of 1980 values per year. Error bars represent the $1 \sigma$ variance as obtained from the residuals of the linear fit.

Figure 8 shows TO3 trends relative to 1980 values for the post peak-EESC $2000-2009$ period. The values shown here are total trends $\hat{\omega}_{12}=\hat{\omega}_{1}+\hat{\omega}_{2}$. Trends are generally close to zero, with the notable exception of relatively strong positive trends in the polar areas during winter and spring. However, none of the observed trends is significant at more than $\sim 1$ standard deviation. In this period, trend patterns from $t t$ and $c c$ runs show only small differences and are both in good agreement with observations; $t T$ is almost indistinguishable from $t t$ except for Antarctic spring. The tendency of observed TO3 towards more positive trends may be related to very strong increases in observed upper stratospheric ozone that are not present in the model (see Sect. 5.3). Given the similarity of modelled trends with and without changing EESC, it is obvious that most of the trends during this period are due to changing meteorological conditions rather than changing chemical composition. This is expected, as the decrease of EESC during the period 2000-2009 is only around $10 \%$ of previous increases, and even less at high latitudes.

Even though no significantly $(2 \sigma)$ positive seasonal trend in the post peak-EESC period is detectable yet, changes in trends between the two analysis periods are obvious from Figs. 7 and 8. A significant change in TO3 trend has been characterized as the first step of ozone recovery (Reinsel et al., 2002; Newchurch et al., 2003; Yang et al., 2008), and has already been claimed for different atmospheric regions (Newchurch et al., 2003; Yang et al., 2008). Figure 9 shows the level of significance of a presumed change in seasonal TO3 trend, which is calculated here as $\hat{\omega}_{2} / \sigma_{\hat{\omega}_{2}}$. A trend change may be regarded significant at the 95 (99.7, $66.7) \%$ level if $\hat{\omega}_{2} / \sigma_{\hat{\omega}_{2}}>2(3,1)$. Contrary to Figs. 7 and 8 , only the TOMS/SBUV merged dataset (aerosol and solar signal removed) is used here as a reference, in order not to artificially lengthen the relevant trend change period. There is good agreement between TOMS/SBUV and $t t$ trend changes; in the SH, TOMS/SBUV shows a higher significance of trend change (up to 4 standard deviations during Antarctic summer). In this regard, it is noteworthy that trend changes in the original TOMS/SBUV time series without removal of solar and aerosol signal are in almost perfect agreement to $t t$ in Antarctic SON and to $t T$ in Antarctic DJF. The positive trend changes observed in TOMS/SBUV are consistent with results presented by Reinsel et al. (2005), who analysed the whole monthly TOMS/SBUV time series in one piece without separation into seasonal trends. The positive change in $t t(t T)$ trend is significant at $2 \sigma(3 \sigma)$ in 


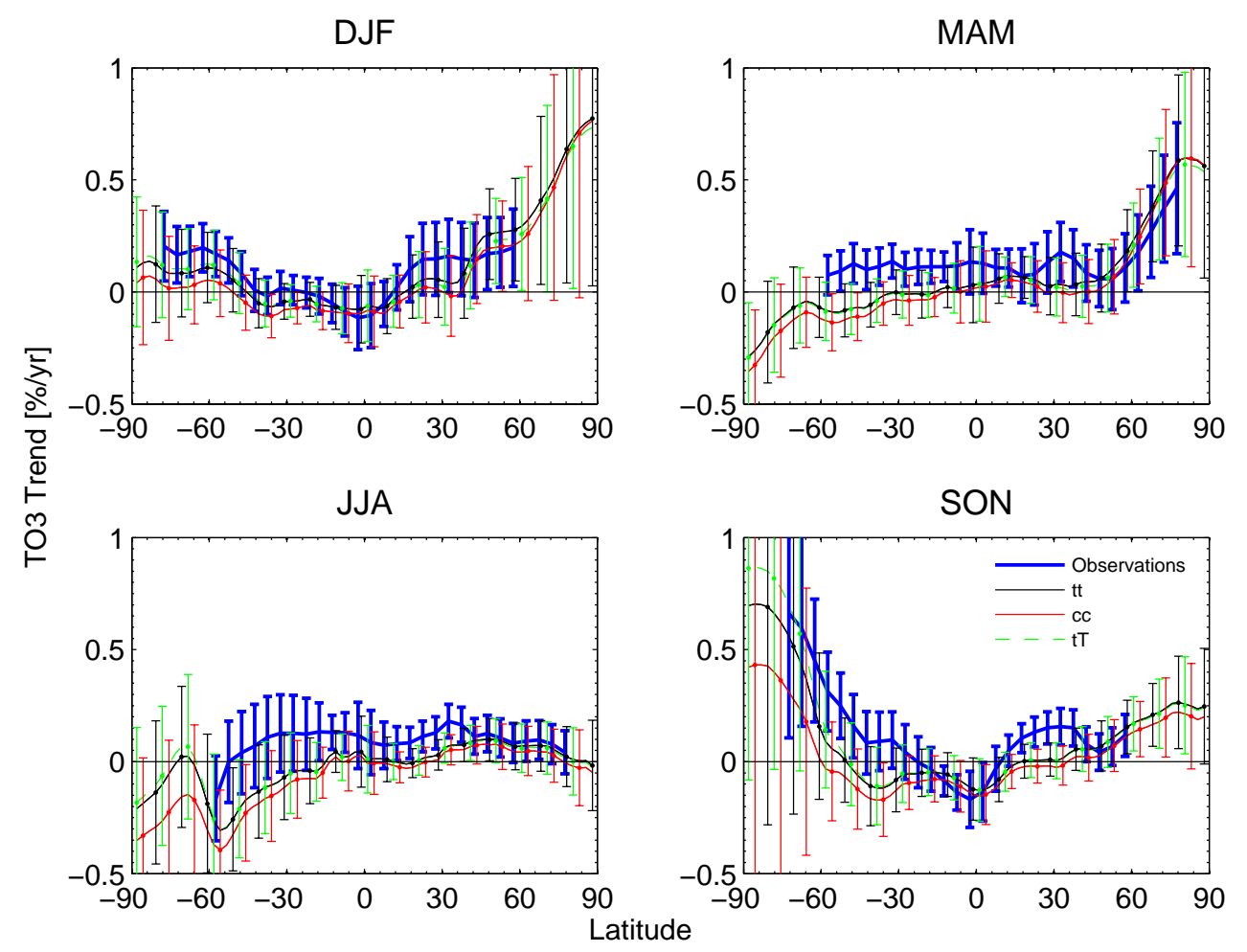

Fig. 8. Like Fig. 7, but for the 2000-2009 period. Modelled TO3 trends are compared to the combined TOMS/SBUV+ GOME/SCIAMACHY/GOME2 TO3 trends ("Observations"), obtained from the time series with solar and aerosol signals removed. Total trends $\left(\hat{\omega}_{12}=\hat{\omega}_{1}+\hat{\omega}_{2}\right)$ from model runs with EESC-dependent chemistry and polar chemistry ( $t t$, black line, and $t T$, green dashed line) and constant conditions ( $c c$, red line) are shown. Trends are given in percent of 1980 values per year. Error bars represent the $1 \sigma$ variance as obtained from the residuals of the linear fit.

Antarctic spring and summer. Without following the detailed treatment by Yang et al. (2008), this confirms that a positive trend change has occurred in Antarctic spring, and is reproduced by our CTM. However, part of this positive change in trend is related to changing meteorology, as indicated by the marginally significant $(1 \sigma)$ change in $c c$ trend. In addition, $t t$ and $t T$ runs show significant changes in $\mathrm{NH}$ midlatitude trends during summer and fall, which are equally related to marginally significant positive changes in the $c c$ trends.

While the piecewise linear regression model applied here to the entire time span allows us to make useful statements about whether changes in long-term trends have occurred, it is not necessarily the most appropriate description of the TO3 evolution itself during the second analysis period (20002009). In several latitude regions, the TO 3 time series rather follows a steep ascent during the late 1990s and then levels off during the 2000-2009 decade (see Fig. 1).

\subsection{Profile ozone trends}

Here we provide a short analysis of ozone profile trends to investigate to what extent the CTM reproduces the observed vertical distribution of ozone trends. In order to increase significance of profile trends, we analyse the whole monthly time series by taking into account its autocorrelation, as described in Sect. 5.1. Figure 10 shows annual mean trends in ozone number density for mid-latitudes and tropics in the 1979-1999 period. Trends from the "full" timedependent run $t t$ are shown in comparison to SBUV observations and purely meteorological trends from run $c c$. SBUV observations are taken from the SBUV merged dataset (zonal $5^{\circ}$ grid). Error bars represent $1 \sigma$ uncertainty of the trend estimate as calculated from Eq. (6).

General features of observed trends are similar for all considered latitude bands. In the 1979-1999 period, a large downward trend is observed in the upper stratosphere with peak values about $-0.6 \% \mathrm{yr}^{-1}$ at $\sim 1500 \mathrm{~K} / \sim 42 \mathrm{~km}$, a nearzero or even positive trend around $600 \mathrm{~K} / 25 \mathrm{~km}$, and a strong negative trend in the lower stratosphere around $380 \mathrm{~K} / 16 \mathrm{~km}$, which resembles the upper stratospheric trend in magnitude. Modelled trends do not fully capture the magnitude of the upper stratospheric trend in the SBUV dataset, a behaviour which may be related to issues with temperature trends in the reanalysis data used (ERA-40 and ERA-Interim datasets exhibit considerable differences in upper stratospheric temperature trends during their period of overlap), or point to difficulties within the Linoz chemistry scheme. 

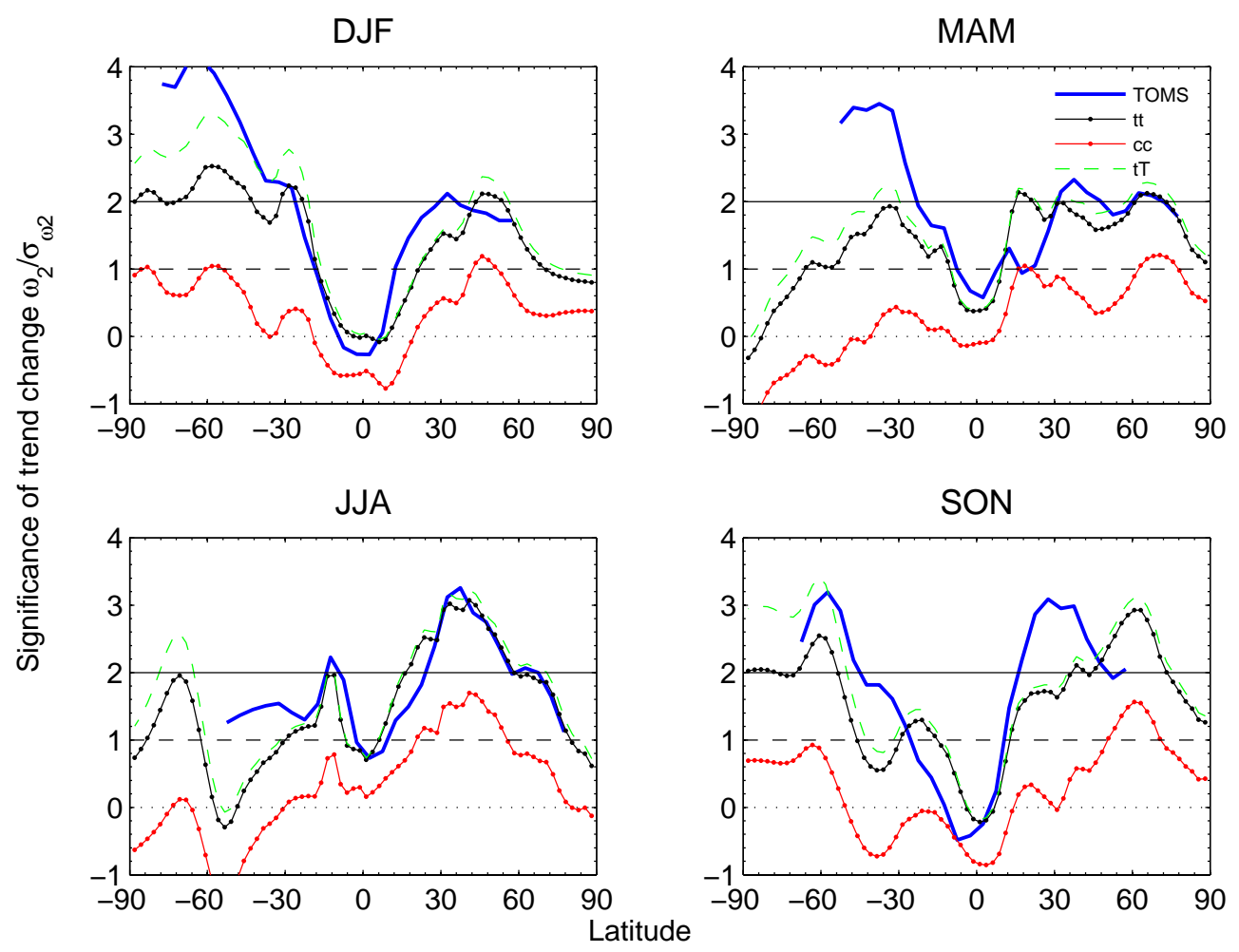

Fig. 9. Change in linear trend between the two analysis periods, 1979-1999 and 2000-2009, expressed in terms of standard deviations in order to provide a measure of its significance. Model runs with changing chemical composition ( $t t$, black line, and $t T$, green dashed line) are compared to the model run with constant chemical composition ( $c c$, red) and TOMS/SBUV satellite observations (blue). Contrary to Figs. 7 and 8, only the TOMS/SBUV dataset is used as a reference, in order to avoid artificial lengthening of the satellite time series in the trend-change period.

The strong upper stratospheric decrease in $t t$ is mostly attributable to changing atmospheric composition (in particular, increasing EESC acting through the $\mathrm{ClO}_{\mathrm{X}}$ cycle) since the $c c$ trend is either close to zero or positive.

There has been a scientific discussion about whether or not a trend in lower stratospheric tropical ozone is present (Eyring et al., 2010). In the model runs analysed here, a significant negative trend is obvious in tropical ozone between $\sim 360-550 \mathrm{~K}(\sim 15-22 \mathrm{~km})$ that is entirely a result of meteorological changes (possibly a strengthening of the BrewerDobson circulation), as it approximately equals the trend in the $c c$ model run. In the mid-latitudes the changing chemical composition of the stratosphere contributes significantly to the negative trend during 1979-1999 (visible as difference between $t t$ and $c c$ ).

In the 2000-2009 analysis period, modelled trends are generally close to zero or positive. Agreement between modelled and SBUV trends is reasonable only below $\sim 35 \mathrm{~km}$. Above this altitude, the SBUV dataset shows a large positive trend that exceeds the preceding negative trend by a factor of 2 in absolute numbers. Since the decrease in EESC during recent years is considerably slower than its increase before, the magnitude of the observed trend is puzzling and can hardly be explained by changing EESC loading of the stratosphere. In the tropical lower stratosphere, the picture is inconclusive in the 2000-2009 period, as the negative trend observed before is not sustained in equal magnitude. A marginally significant negative trend is present in the lowermost model levels, which are however located in the upper troposphere in the tropics.

\section{Contributions to column ozone trends}

In this section, differences in modelled column ozone trends are analysed in order to distill contributions from different processes. In particular, we seek to quantify the effects of atmospheric composition changes on TO3 evolution, acting through polar heterogeneous chemistry and export of ozonedepleted air, as well as through gas phase chemistry, as opposed to meteorological (transport and temperature) effects.

In order to separate effects of changing atmospheric composition on gas-phase chemistry and polar chemistry, we analyse differences of runs $t t, t c$, and $c c$. While $t t$ contains full temporal evolution of gas phase and heterogeneous chemistry (ozone decay rate $1 / \tau \propto$ EESC), $c c$ 
Trend 1: 1979-1999
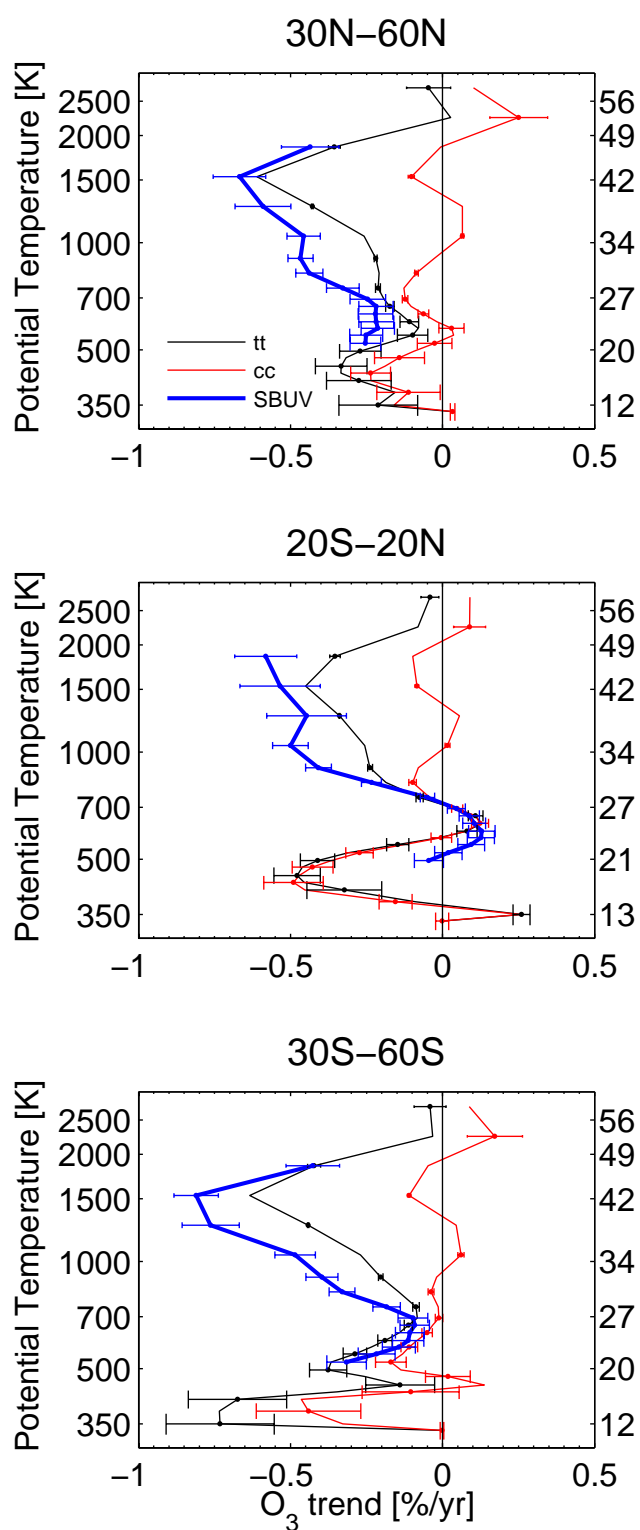

Trend 1+2: 2000-2009
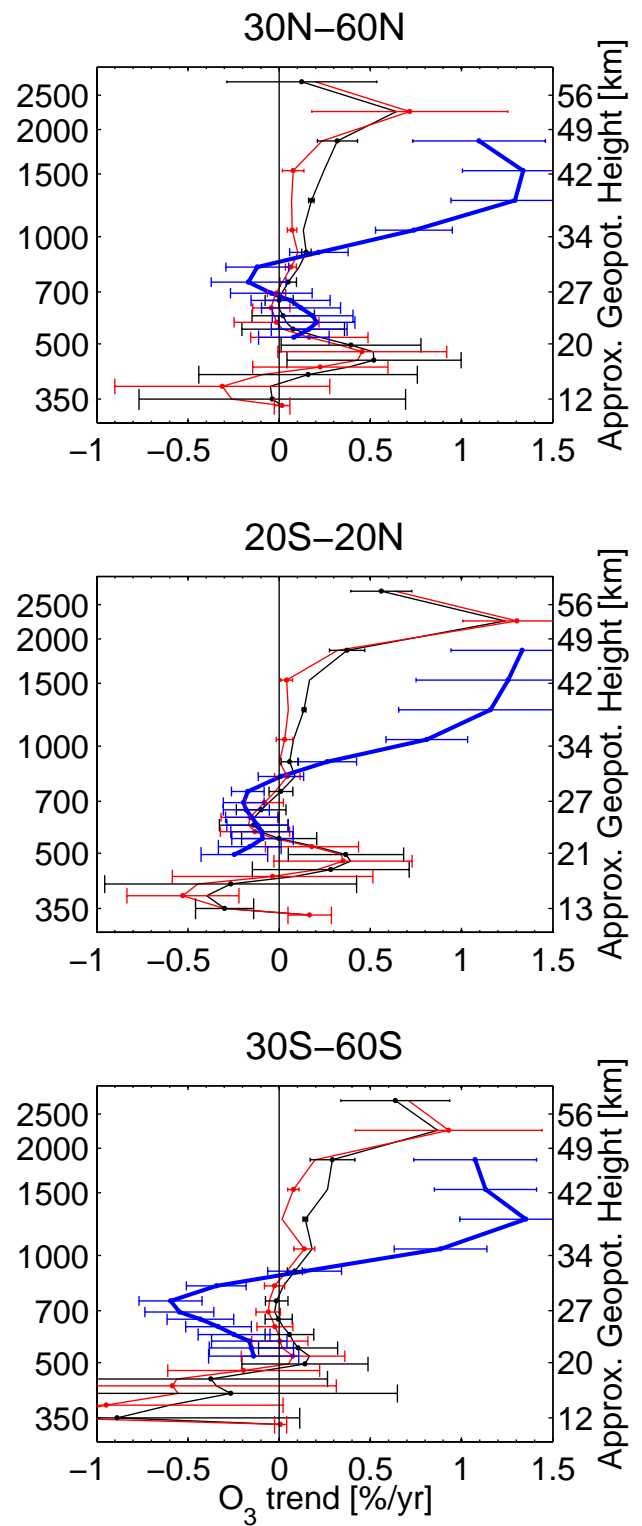

Fig. 10. Modelled ozone number density trends as compared to SBUV ozone trends, in the period 1979-1999 (left), and 2000-2009 (right). Trends from model runs with time-dependent chemistry and polar chemistry ( $t$, black line) and constant chemical conditions $(c c$, red line) are shown. Trends are given in percent of 1980 values per year. Error bars represent the $1 \sigma$ variance as obtained from the residuals of the linear fit.

assumes constant chemical conditions and underlies only meteorological variability. Trends of $t c-c c$ can be interpreted as the contribution of changing atmospheric composition to ozone trends through gas phase chemistry, while $t t-t c$ yields the fraction of ozone trends attributable to the effect of ODS changes on polar chemistry. Figure 11 displays these difference trends for the 1979-1999 period, along with the $c c$ trend and the $t t$ trend as zonal means for all seasons. Again, also the effect of a stronger scaling of the polar ozone decay rate $1 / \tau \propto \mathrm{EESC}^{2}$ is shown by the $t T-t c$ difference, and the $t T$ trend is included as a reference for the overall trend in this case. Note that trends are given as absolute values in $\mathrm{DU} \mathrm{yr}^{-1}$ here, contrary to Fig. 7 which relates them to 1980 TO3 values. The reason is the obvious ambiguity as to which reference value trends of $\Delta \mathrm{TO} 3$ should be related to. Error bars in Fig. 11 correspond to $1 \sigma$ standard variation of the residuals. Since the differences $t c-c c$ and $t t-t c$ originate in information that is put into the CTM (i.e., 

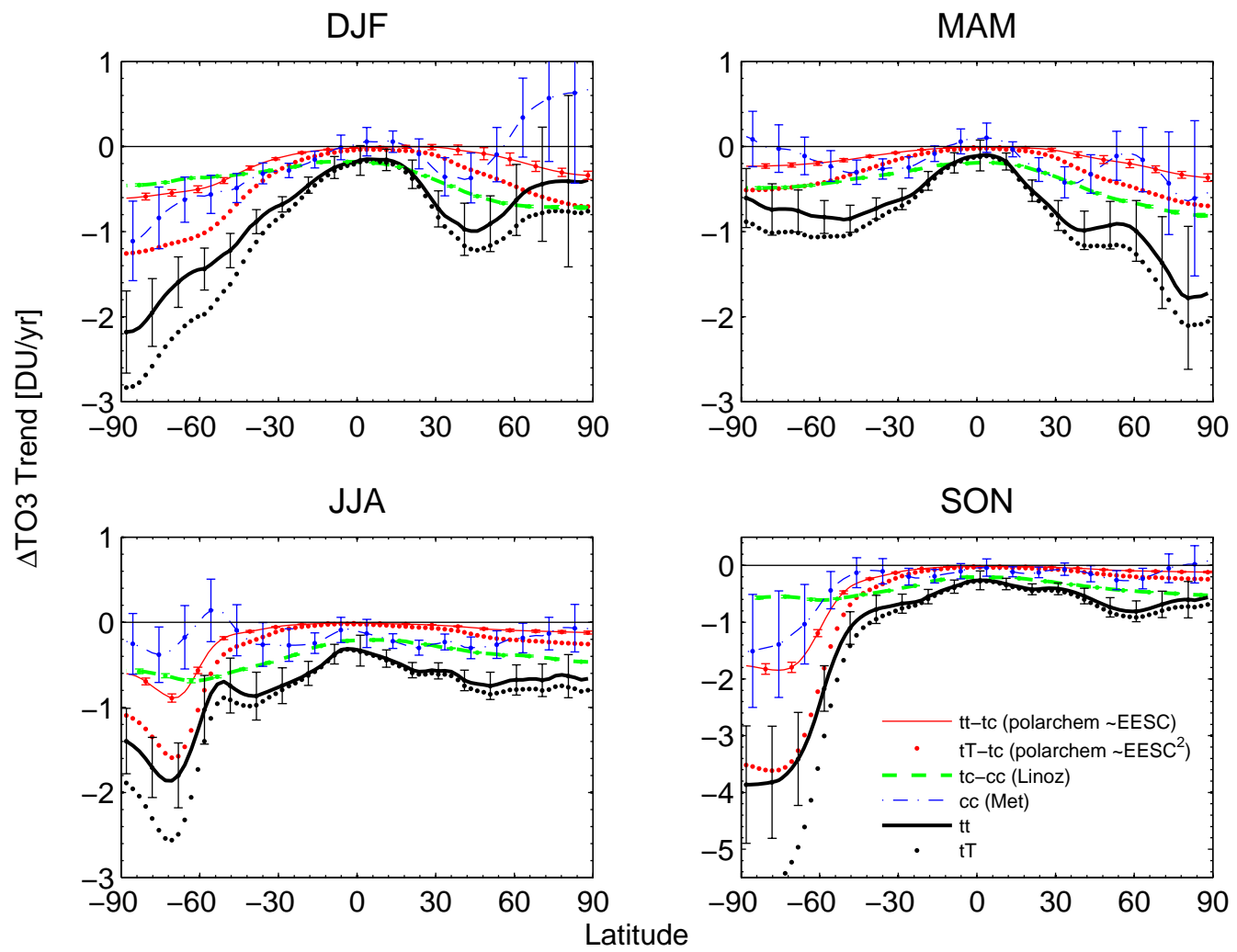

Fig. 11. Attribution of TO3 trends in the 1979-1999 period to effects of ODS change on gas phase chemistry $(t c-c c)$, ODS change on polar chemistry $(t t-t c$ for polar chemistry $\propto$ EESC, and $t T-t c$ for polar chemistry $\propto$ EESC), and natural variability under constant atmospheric composition $(c c)$. Total trends are shown as a reference $(t t$ and $t T)$.

the linear interpolation of Linoz tables and the linear scaling of the polar chemistry with EESC), it is not surprising that the residuals of a linear fit to these differences are small. For this reason, the error bars of $t c-c c$ and $t t-t c$ should be viewed with caution, as they are directly influenced by the design of our study and do not correspond to actual "uncertainty". Nevertheless, we include them here to give a feeling of how well determined the differences between the model runs are, as compared to the large variability in meteorological $(c c)$ trends. For enhanced readability of Fig. 11 error bars for $t T$ and $t T-t c$ are left out, as they are of comparable magnitude to $t t$ and $t t-t c$ errorbars, respectively.

Changes in in-situ (gas phase) chemistry $(t c-c c)$ make up for the main contribution to observed trends outside the polar latitudes. In all seasons except $\mathrm{SH}$ midlatitude summer (DJF), more than $50 \%$ of the $t t$ trend is explained by gas phase chemistry changes. In absolute terms, effects of ODS changes on gas phase chemistry are generally weakest in tropical latitudes $\left(\sim-0.2 \mathrm{DU} \mathrm{yr}^{-1}\right)$ and more pronounced in extratropical latitudes. Seasonality is low, resulting in an almost symmetric structure peaking during polar winter and spring $\left(\sim-0.7 \mathrm{DU} \mathrm{yr}^{-1}\right)$, and a slightly weaker trend in polar summer and autumn $\left(\sim-0.5 \mathrm{DU} \mathrm{yr}^{-1}\right)$.
As expected, influence of ODSs on ozone trends through polar heterogeneous chemistry $(t t-t c$ or $t T-t c)$ shows a pronounced seasonality and latitude dependence. Large differences are present between $t t-t c$ and $t T-t c$ due to the different scaling of polar ozone destruction with EESC. $t t-t c$ and $t T-t c$ trends may be regarded as the upper and lower limits of polar chemistry contributions to column ozone trends. Effects of polar ozone depletion are observed during SH winter, peaking at high southern latitudes during spring $\left(\sim-1.8 \mathrm{DU} \mathrm{yr}^{-1}\right.$ for $t t-t c$ and $\sim-3.5 \mathrm{DU} \mathrm{yr}^{-1}$ for $t T-t c)$, after which the ozone depleted air masses are distributed to mid-latitudes where they cause a trend of $\sim-0.35 \mathrm{DU} \mathrm{yr}^{-1}\left(\sim-0.7 \mathrm{DU} \mathrm{yr}^{-1}\right)$ or $\sim 35 \%(\sim 50 \%)$ of the total observed $t t(t T)$ trend during SON and DJF. Due to the warmer Arctic vortex and its earlier breakup, heterogeneous ozone depletion is generally less severe in the $\mathrm{NH}$ and peaks earlier in spring than in the Antarctic, resulting in a peak trend at high northern latitudes of $-0.35 \mathrm{DU} \mathrm{yr}^{-1}$ $\left(-0.7 \mathrm{DU} \mathrm{yr}^{-1}\right)$ for linear (quadratic) polar chemistry during DJF and MAM. Through dispersion to lower latitudes this effect contributes around $-0.15 \mathrm{DU} \mathrm{yr}^{-1}\left(-0.3 \mathrm{DU} \mathrm{yr}^{-1}\right)$ or $\sim 15 \%(\sim 30 \%)$ to $t t(t T)$ column ozone trends in NH midlatitude spring. Near the equator the effect of ODSs through 


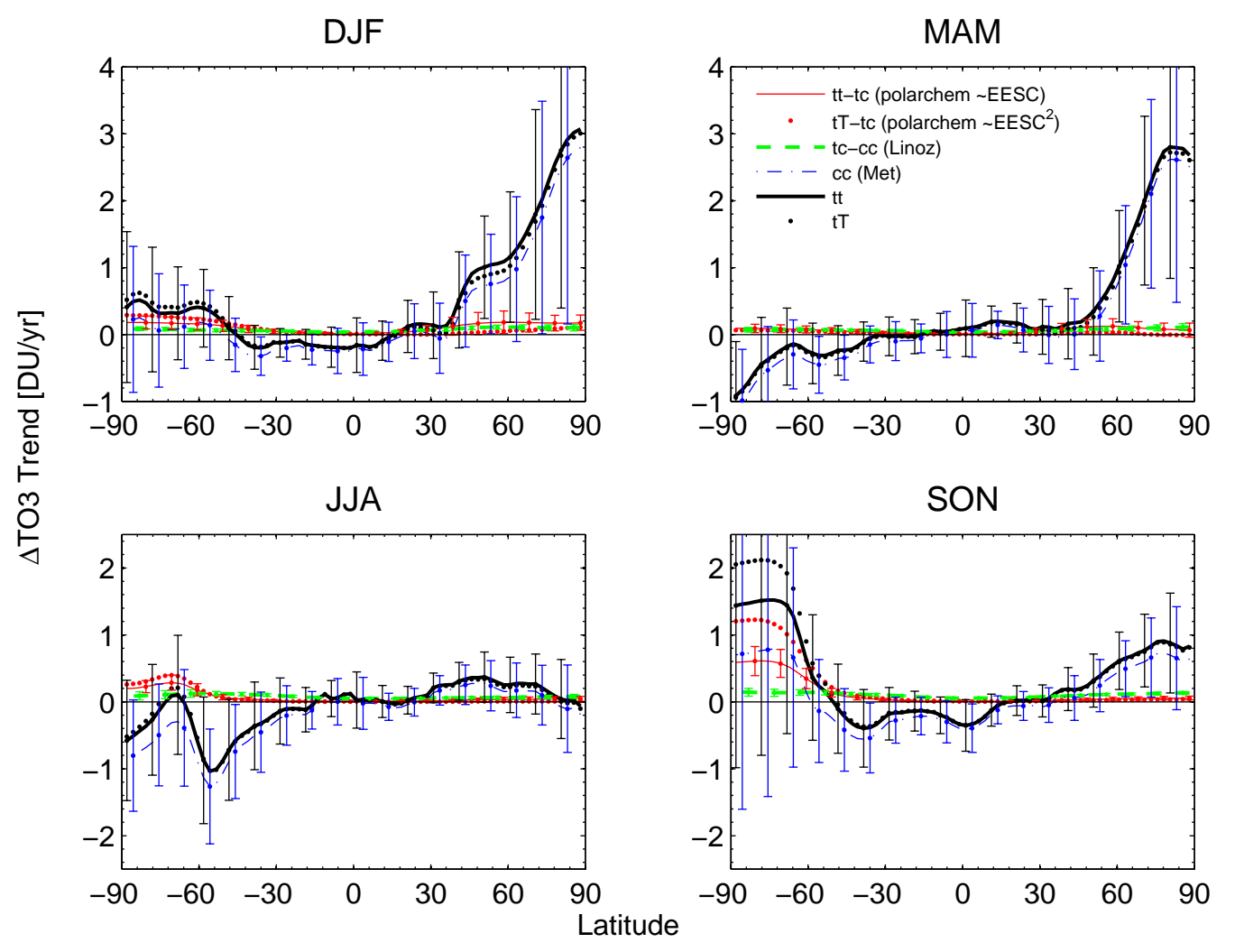

Fig. 12. Like Fig. 11, but for the 2000-2009 period. Attribution of TO3 trends to effects of ODS change on gas phase chemistry $(t c-c c)$, ODS change on polar chemistry $(t t-t c$ and $t T-t c$, respectively), and natural variability under constant atmospheric composition ( $c c)$. Total trends are shown as a reference $(t t$ and $t T)$.

export of polar chemistry is small, as to be expected (less than $-0.05 \mathrm{DU} \mathrm{yr}^{-1}$ or $10 \%$ of the total observed trend with either scaling of polar chemistry). Note that due to the large uncertainties in total $(t t)$ trends, percentages of different contributions are also subject to large uncertainties although the absolute trend differences are well determined (see errorbars in Fig. 11).

One may also take $c t-c c$ as the effect of ODS changes acting through polar chemistry and its export, and conversely $t t-c t$ as the effect of ODS changes acting via gas phase chemistry. These differences show very similar trends to the ones described above, agreeing to these within less than $\pm 0.1 \mathrm{DU} \mathrm{yr}^{-1}$ (not shown in Fig. 11 to enhance readability).

The values of trends caused by ODS changes described here compare well to results obtained by Chipperfield (2003), who reported that in a similar modelling study for the 19791998 period, the total effect of increasing halogen loadings (in-situ chemistry + polar chemistry) led to a reduction of midlatitude column ozone of around 20 DU in the SH and $10 \mathrm{DU}$ in the NH. In our study the corresponding amounts are $15 \mathrm{DU}(20 \mathrm{DU})$ in the SH and $11 \mathrm{DU}$ (14 DU) in the $\mathrm{NH}$ in the $t t(t T)$ runs.
The magnitude of trends caused by meteorological changes alone $(c c)$ is comparable to those of the trends caused by changing ODSs, ranging between -0.5 and $+0.5 \mathrm{DU} \mathrm{yr}^{-1}$ except for polar latitudes during the ozone hole season in spring. As noted before, the strong negative trend in SH polar latitudes during SON $\left(\sim-1.5 \mathrm{DU} \mathrm{yr}^{-1}\right)$ may clearly be interpreted as a sign of dynamical feedback of ozone depletion, as are most probably also the strong negative $c c$ trends at high southern latitudes during DJF $\left(\sim-1 \mathrm{DU} \mathrm{yr}^{-1}\right)$ and high northern latitudes during MAM $\left(\sim-0.9 \mathrm{DU} \mathrm{yr}^{-1}\right)$. In the $\mathrm{NH}$ midlatitudes, meteorological changes contribute around $30-40 \%$ year-round to total ozone trends, while in the SH midlatitudes their contribution is comparably large during summer but negligible during winter months. The value of $\sim 35 \%$ contribution to $\mathrm{NH}$ midlatitude trends in spring lies between values reported by Randel et al. (2002) (20-30\%), Steinbrecht et al. (1998) (30\%), Hadjinicolaou et al. (2002) ( $\gtrsim 30 \%)$, and those obtained by Hood et al. (1997) (up to 50\%).

Figure 12 shows the trend decomposition as in Fig. 11 but for the 2000-2009 period. A distinct positive trend in column ozone is visible as an effect of ODS decreases on gas phase chemistry $(t c-c c)$, while effects of a changing polar 
chemistry $(t t-t c$ and $t T-t c)$ are not yet significant except for the ozone hole season (Antarctic SON), where they are directly imposed by the EESC scaling. During Antarctic spring, linear response of polar ozone depletion to EESC $(t t-t c)$ causes a trend of $+0.6 \mathrm{DU} \mathrm{yr}^{-1}$, while quadratic dependency causes a trend of $+1.1 \mathrm{DU} \mathrm{yr}^{-1}$. Overall, meteorological variability dominates, showing strong variations with season and latitude. In particular, the strong and marginally significant trend in NH TO3 during winter and spring is almost entirely caused by meteorology and to less than $10 \%$ attributable to ODS changes.

\section{Conclusions}

In this study, we have analyzed ozone trends in a set of sensitivity runs conducted with our stratospheric CTM. Ozone trends are calculated for the two periods 1979-1999 and 2000-2009 using piecewise linear trends. The stratospheric chlorine loading has roughly doubled between 1980 and the late 1990s, peaked around the turn of the century, at different times for different latitudes, and since begun to slowly decrease. Our two linear trend periods thus roughly correspond to periods of increasing and decreasing stratospheric halogen loading, respectively.

Modelled TO3 inter-annual variability and trends are in excellent agreement with TOMS/SBUV as well as GOME/SCIAMACHY/GOME2 observations for both periods. A large fraction of the remaining differences between modelled and observed TO3 are well explained by the influences of the solar cycle and variations in aerosol concentrations, which are not explicitly accounted for in our CTM.

In the period 1979-1999 modelled TO3 trends at midlatitudes are dominated by changes in in-situ chemistry, contributing to bout $50 \%$ of the overall $\mathrm{TO} 3$ trend in NH midlatitudes and $30-80 \%$ at SH mid-latitudes, with smallest relative contribution during spring. Polar ozone depletion and its export into mid-latitudes contributes significantly to the TO3 trends: about $35-50 \%$ of the modelled springtime TO3 trend at SH mid-latitudes and about $15-30 \%$ at $\mathrm{NH}$ mid-latitudes are attributable to trends in polar ozone depletion. Changes in meteorology have contributed to the modelled TO3 loss during the 1979-1999 period in both hemispheres and almost all seasons, with the largest impact on SH high-latitudes during spring.

Trends and inter-annual variability of $\mathrm{TO} 3$ at high latitudes are well reproduced by the CTM; CTM runs with a linear scaling of ozone loss with EESC slightly underestimate observed TO3 trends, while CTM runs with a quadratic scaling of polar ozone loss with EESC overestimate observed TO3 trends. For both assumptions (linear or quadratic scaling with EESC) the model calculates substantial polar ozone depletion (diagnosed as differences between model runs with and without polar ozone loss) in Antarctic spring already before 1980. As the absolute amount of modelled polar ozone depletion differs significantly between CTM runs us- ing ERA-40 and ERA-Interim re-analyses and depends critically on the assumed scaling of ozone loss with EESC in our simplified approach, we do not attempt to quantify the pre-1980 Antarctic ozone loss here, but note that this is an interesting finding worth to be explored in more detail using comprehensive full chemistry model calculations.

Over the period 2000-2009 linear trends in modelled TO3, which agree well with observed TO3 trends, are dominated by changes in meteorology, as expected for the yet small decrease in EESC over this period. No significant TO3 trends are present in this decade alone, and we cannot yet distinguish an overall positive TO3 trend. Effects of decreasing ODS loading are visible after 2000 as differences between model runs, with EESC changes responsible for a positive modelled TO3 trend of around $+0.6-1.2 \mathrm{DU} \mathrm{yr}^{-1}$ in the period 2000-2009. Due to strong inter-annual variability of high-latitude TO3, these trends are yet too small to allow a distinction from the expected evolution in case of constant EESC levels.

While the TO3 trends themselves are not statistically significant over the period 2000-2009, changes in linear trends between 1978-1999 and 2000-2009 are significant at $\geq 2$ standard deviations for Antarctic spring and summer and at $\mathrm{NH}$ and SH mid-latitudes during most seasons for both observed and modelled TO3. However, also the model runs without ODS changes show marginally significant ( $\geq 1$ standard deviation) trend changes, indicating that changes in meteorology have contributed roughly half to the observed trend changes. No significant TO3 trend changes are observed in the tropics.

Modelled ozone profile trends show a negative maximum in the tropical lower stratosphere of about $0.5 \% \mathrm{yr}^{-1}$ during the 1979-1999 period, almost exclusively as a result of changes in meteorology. However, whether this is in agreement with observations or not is currently inconclusive. The negative trend in lower stratospheric tropical ozone is not sustained in equal magnitude during the 2000-2009 period. Modelled TO3 trends in the tropics are not statistically different from zero, in agreement with TOMS/SBUV and GOME/SCIAMACHY/GOME2 observations.

Overall we find that the evolution of TO3 over the past decade can be reproduced well by our CTM driven with meteorological reanalyses, indicating that the evolution of ozone over the past decade is consistent with our current understanding of ozone chemistry.

Acknowledgements. We thank Juno Hsu and Michael Prather (UC Irvine) for providing the Linoz tables used in this study and sharing their expertise with us. We thank NASA GSFC (TOMS Science Team) for providing the TOMS and SBUV data (Merged Ozone Dataset) used in this study (obtained from http://acdb-ext.gsfc.nasa.gov/Data \_services/merged/).

EESC was obtained from the NASA automailer system, online at: http://acdb-ext.gsfc.nasa.gov/Data \_services/automailer/. ECMWF ERA-40 and ERA-Interim data used in this study have been obtained from the ECMWF Data Server through the special 
project DECDIO. Parts of this work have been funded by the German Research Foundation (DFG) under the priority programme "CAWSES - Climate and Weather of the Sun Earth System". Work related to merging the GOME, SCIAMACHY, and GOME2 total ozone record has been funded in parts by the BMBWi Project ENVIVAL-LIFE and DFG Research Unit "Stratospheric Change and its Role for Climate Prediction” (SHARP).

Edited by: M. Dameris

\section{References}

Bovensmann, H., Burrows, J. P., Buchwitz, M., Frerick, J., Noel, S., Rozanov, V. V., Chance, K. V., and Goede, A. P. H.: SCIAMACHY: Mission objectives and measurement modes, J. Atmos. Sci., 56, 127-150, 1999.

Bracher, A., Lamsal, L. N., Weber, M., Bramstedt, K., ColdeweyEgbers, M., and Burrows, J. P.: Global satellite validation of SCIAMACHY $\mathrm{O}_{3}$ columns with GOME WFDOAS, Atmos. Chem. Phys., 5, 2357-2368, doi:10.5194/acp-5-2357-2005, 2005.

Braesicke, P. and Pyle, J. A.: Changing ozone and changing circulation in northern mid-latitudes: Possible feedbacks?, Geophys. Res. Lett., 30, 1059, doi:10.1029/2002GL015973, 2003.

Callies, J., Corpaccioli, E., Eisinger, M., Hahne, A., and Lefebvre, A.: GOME-2 - METOP's second-generation sensor for operational ozone monitoring, ESA Bull., 102, 28-36, 2000.

Chipperfield, M. P.: A three-dimensional model study of longterm mid-high latitude lower stratosphere ozone changes, Atmos. Chem. Phys., 3, 1253-1265, doi:10.5194/acp-3-1253-2003, 2003.

Coldewey-Egbers, M., Weber, M., Lamsal, L. N., de Beek, R., Buchwitz, M., and Burrows, J. P.: Total ozone retrieval from GOME UV spectral data using the weighting function DOAS approach, Atmos. Chem. Phys., 5, 1015-1025, doi:10.5194/acp5-1015-2005, 2005.

Dhomse, S., Weber, M., Wohltmann, I., Rex, M., and Burrows, J. P.: On the possible causes of recent increases in northern hemispheric total ozone from a statistical analysis of satellite data from 1979 to 2003, Atmos. Chem. Phys., 6, 1165-1180, doi:10.5194/acp-6-1165-2006, 2006.

Eyring, V., Shepherd, T. G., and Waugh, D. W. (Eds.): SPARC Report on the Evaluation of Chemistry-Climate Models, SPARC Report No. 5, WCRP-132, WMO/TD-No. 1526, 2010.

Feng, W., Chipperfield, M. P., Dorf, M., Pfeilsticker, K., and Ricaud, P.: Mid-latitude ozone changes: studies with a 3-D CTM forced by ERA-40 analyses, Atmos. Chem. Phys., 7, 2357-2369, doi:10.5194/acp-7-2357-2007, 2007.

Fortuin, J. F. P. and Kelder, H.: An ozone climatology based on ozonesondes and satellite measurements, J. Geophys. Res., 103, 31709-31734, 1998.

Hadjinicolaou, P., Jrrar, A., Pyle, J. A., and Bishop, L.: The dynamically driven long-term trend in stratospheric ozone over northern middle latitudes, Q. J. Roy Meteor. Soc., 128, 1393-1412, 2002.

Hadjinicolaou, P., Pyle, J. A., and Harris, N. R. P.: The recent turnaround in stratospheric ozone over northern middle latitudes: A dynamical modeling perspective, Geophys. Res. Lett., 32, 12821, doi:10.1029/2005GL022476, 2005.
Harris, N., Hudson, R., and Phillips, C. (Eds.): Assessment of trends in the vertical distribution of ozone. SPARC Rep. 1, WMO-Ozone Research and Monitoring Project Rep. 43, 1998.

Harris, N. R. P., Kyrö, E., Staehelin, J., Brunner, D., Andersen, S.B., Godin-Beekmann, S., Dhomse, S., Hadjinicolaou, P., Hansen, G., Isaksen, I., Jrrar, A., Karpetchko, A., Kivi, R., Knudsen, B., Krizan, P., Lastovicka, J., Maeder, J., Orsolini, Y., Pyle, J. A., Rex, M., Vanicek, K., Weber, M., Wohltmann, I., Zanis, P., and Zerefos, C.: Ozone trends at northern mid- and high latitudes - a European perspective, Ann. Geophys., 26, 1207-1220, doi:10.5194/angeo-26-1207-2008, 2008.

Harris, N. R. P., Lehmann, R., Rex, M., and von der Gathen, P.: A closer look at Arctic ozone loss and polar stratospheric clouds, Atmos. Chem. Phys., 10, 8499-8510, doi:10.5194/ acp-10-8499-2010, 2010.

Hood, L. L., McCormack, J. P., and Labitzke, K.: An investigation of dynamical contributions to midlatitude ozone trends in winter, J. Geophys. Res., 102, 13079-13093, 1997.

Hsu, J. and Prather, M. J.: Stratospheric variability and tropospheric ozone, J. Geophys. Res., 114, D06102, doi:10.1029/ 2008JD010942, 2009.

Kiesewetter, G., Sinnhuber, B.-M., Vountas, M., Weber, M., and Burrows, J. P.: A Long-term Stratospheric Ozone Dataset from Assimilation of Satellite Observations: High-Latitude Ozone Anomalies, J. Geophys. Res., 115, D10307, doi:10.1029/ 2009JD013362, 2010.

McLinden, C. A., Olsen, S. C., Hannegan, B., Wild, O., Prather, M. J., and Sundet, J.: Stratospheric ozone in 3-D models: A simple chemistry and the cross-tropopause flux, J. Geophys. Res., 105, 14653-14665, 2000.

Newchurch, M. J., Yang, E.-S., Cunnold, D. M., Reinsel, G. C., Zawodny, J. M., and Russell III, J. M.: Evidence for slowdown in stratospheric ozone loss: First stage of ozone recovery, J. Geophys. Res., 108, 4507, doi:10.1029/2003JD003471, 2003.

Newman, P. A., Nash, E. R., Kawa, S. R., Montzka, S. A., and Schauffler, S. M.: When will the Antarctic ozone hole recover?, Geophys. Res. Lett., 33, L12814, doi:10.1029/2005GL025232, 2006.

Prather, M.: Catastrophic Loss of Stratospheric Ozone in Dense Volcanic Clouds, J. Geophys. Res., 97, 10187-10191, 1992.

Randel, W. and Wu, F.: Cooling of the Arctic and Antarctic Polar Stratospheres due to Ozone Depletion, J. Clim., 12, 1467-1469, 1999.

Randel, W. J., Wu, F., Russell III, J. M., Waters, J. W., and Froidevaux, L.: Ozone and temperature changes in the stratosphere following the eruption of Mt. Pinatubo, J. Geophys. Res., 100, 16753-16764, 1995.

Randel, W. J., Wu, F., and Stolarski, R.: Changes in column ozone correlated with the stratospheric EP flux, J. Met. Soc. Japan, 80, 849-862, 2002.

Reinsel, G. C., Weatherhead, E. C., Tiao, G. C., Miller, A. J., Nagatani, R. M., Wuebbles, D. J., and Flynn, L. E.: On detection of turnaround and recovery in trend for ozone, J. Geophys. Res., 107, 4078, doi:10.1029/2001JD000500, 2002.

Reinsel, G. C., Miller, A. J., Weatherhead, E. J., Flynn, L. E., Nagatani, R. M., Tiao, G. C., and Wuebbles, D. J.: Trend analysis of total ozone data for turnaround and dynamical contributions, J. Geophys. Res., 110, 16306, doi:10.1029/2004JD004662, 2005.

Rex, M., Salawitch, R. J., von der Gathen, P., Harris, N. R. P., 
Chipperfield, M. P., and Naujokat, B.: Arctic ozone loss and climate change, Geophys. Res. Lett., 31, L04116, doi:10.1029/ 2003GL018844, 2004.

Searle, K. R., Chipperfield, M. P., Bekki, S., and Pyle, J. A. .: The impact of spatial averaging on calculated polar ozone loss. 2. Theoretical analysis, J. Geophys. Res., 103, 25409-25416, 1998.

Shine, K. P.: The middle atmosphere in the absence of dynamical heat fluxes, Q. J. Roy. Meteor. Soc., 113, 603-633, 1987.

Sinnhuber, B.-M., Weber, M., Amankwah, A., and Burrows, J. P.: Total ozone during the unusual Antarctic winter of 2002, Geophys. Res. Lett., 30, 1580, doi:10.1029/2002GL016798, 2003.

Solomon, S., Portmann, R. W., Garcia, R., Thomason, L. W., Poole, L. R., and McCormick, M.: The role of aerosol variations in anthropogenic ozone depletion at northern midlatitudes, J. Geophys. Res., 101, 6713 - 6727, 1996.

Solomon, S., Portmann, R. W., Garcia, R. R., Randel, W., Wu, F., Nagatani, R., Gleason, J., Thomason, L., Poole, L. R., and McCormick, M. P.: Ozone depletion at mid-latitudes: Coupling of volcanic aerosols and temperature variability to anthropogenic chlorine, Geophys. Res. Lett., 28, 1871-1874, 1998.

Soukharev, B. E. and Hood, L. L.: Solar cycle variation of stratospheric ozone: Multiple regression analysis of long-term satellite data sets and comparisons with models, J. Geophys. Res., 111, D20314, doi:10.1029/2006JD007107, 2006.

Steinbrecht, W., Claude, H., Köhler, U., and Hoinka, K. P.: Correlations between tropopause height and total ozone: Implications for long-term changes, J. Geophys. Res., 103, 19183-19192, 1998.

Stolarski, R. S. and Frith, S. M.: Search for evidence of trend slowdown in the long-term TOMS/SBUV total ozone data record: the importance of instrument drift uncertainty, Atmos. Chem. Phys., 6, 4057-4065, doi:10.5194/acp-6-4057-2006, 2006.

Stolarski, R. S., Douglass, A. R., Steenrood, S., and Pawson, S.: Trends in stratospheric ozone: Lessons learned from a 3D chemical transport model, J. Atmos. Sci., 63, 1028-1041, 2006.
Thomason, L. W. and Peter, T. (Eds.): Assessment of Stratospheric Aerosol Properties (ASAP). SPARC Rep. 4, 2006.

Thomason, L. W., Poole, L. R., and Deshler, T.: A global climatology of stratospheric aerosol surface area density deduced from Stratospheric Aerosol and Gas Experiment II measurements: 1984 1994, J. Geophys. Res., 102, 8967-8976, 1997.

Waibel, A. E., Peter, T., Carslaw, K. S., Oelhaf, H., Wetzel, G., Crutzen, P. J., Pöschl, U., Tsias, A., Reimer, E., and Fischer, H.: Arctic Ozone Loss Due to Denitrification, Science, 283, 2064 2069, doi:10.1126/science.283.5410.2064, 1999.

Weber, M., Dohmse, S., Wittrock, F., Richter, A., Sinnhuber, B.M., and Burrows, J. P.: Dynamical control of $\mathrm{NH}$ and $\mathrm{SH}$ winter/spring total ozone from GOME observations 1995-2002, Geophys. Res. Lett., 30, 1583, doi:10.1029/2002GL016799, 2003.

Weber, M., Lamsal, L. N., Coldewey-Egbers, M., Bramstedt, K., and Burrows, J. P.: Pole-to-pole validation of GOME WFDOAS total ozone with groundbased data, Atmos. Chem. Phys., 5, 1341-1355, doi:10.5194/acp-5-1341-2005, 2005.

Weber, M., Lamsal, L. N., and Burrows, J. P.: Improved SCIAMACHY WFDOAS total ozone retrieval: Steps towards homogenising long-term total ozone datasets from GOME, SCIAMACHY, and GOME2, in: Proc. "Envisat Symposium 2007", Montreux, Switzerland, 23-27 April 2007, ESA SP-636, 2007.

Wohltmann, I., Lehmann, R., Rex, M., Brunner, D., and Mader, J.: A process-oriented regression model for column ozone, J. Geophys. Res., 112, D12 304, doi:10.1029/2006JD007573, 2007.

World Meteorological Organization: Scientific Assessment of of Ozone Depletion: 2006. Global Ozone Research and Monitoring Project - Report No. 50, 2007.

Yang, E.-S., Cunnold, D. M., Newchurch, M. J., Salawitch, R. J., McCormick, M. P., Russell III, J. M., Zawodny, J. M., and Oltmans, S. J.: First stage of Antarctic ozone recovery, J. Geophys. Res., 113, D20308, doi:10.1029/2007JD009675, 2008. 